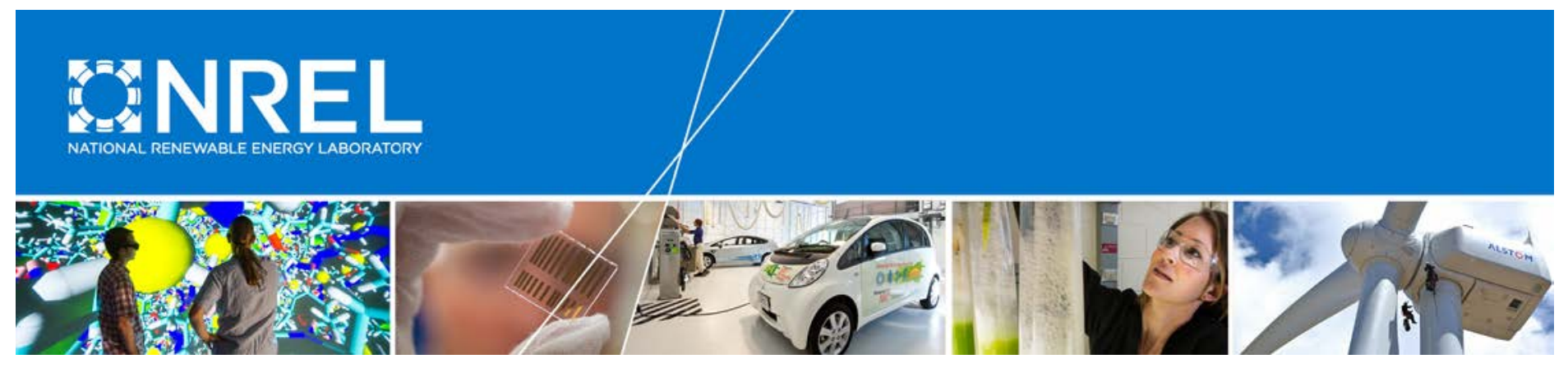

\title{
Clean Energy in City Codes: A Baseline Analysis of Municipal Codification across the United States
}

Jeffrey J. Cook, Alexandra Aznar, Alexander Dane, Megan Day, Shivani Mathur, and Elizabeth Doris National Renewable Energy Laboratory

NREL is a national laboratory of the U.S. Department of Energy Office of Energy Efficiency \& Renewable Energy Operated by the Alliance for Sustainable Energy, LLC

This report is available at no cost from the National Renewable Energy Laboratory (NREL) at www.nrel.gov/publications.

Technical Report

NREL/TP-6A70-66120

December 2016 


\section{Clean Energy in City Codes: A Baseline Analysis of Municipal Codification across the United States}

Jeffrey J. Cook, Alexandra Aznar, Alexander Dane, Megan Day, Shivani Mathur, and Elizabeth Doris

Prepared under Task No. EP61.0201

NREL is a national laboratory of the U.S. Department of Energy Office of Energy Efficiency \& Renewable Energy Operated by the Alliance for Sustainable Energy, LLC

This report is available at no cost from the National Renewable Energy Laboratory (NREL) at www.nrel.gov/publications.

National Renewable Energy Laboratory 15013 Denver West Parkway Golden, CO 80401

303-275-3000 • www.nrel.gov

\section{Technical Report}

NREL/TP-6A70-66120

December 2016

Contract No. DE-AC36-08G028308 


\section{NOTICE}

This report was prepared as an account of work sponsored by an agency of the United States government. Neither the United States government nor any agency thereof, nor any of their employees, makes any warranty, express or implied, or assumes any legal liability or responsibility for the accuracy, completeness, or usefulness of any information, apparatus, product, or process disclosed, or represents that its use would not infringe privately owned rights. Reference herein to any specific commercial product, process, or service by trade name, trademark, manufacturer, or otherwise does not necessarily constitute or imply its endorsement, recommendation, or favoring by the United States government or any agency thereof. The views and opinions of authors expressed herein do not necessarily state or reflect those of the United States government or any agency thereof.

This report is available at no cost from the National Renewable Energy Laboratory (NREL) at www.nrel.gov/publications.

Available electronically at SciTech Connect http:/www.osti.gov/scitech

Available for a processing fee to U.S. Department of Energy and its contractors, in paper, from:

U.S. Department of Energy

Office of Scientific and Technical Information

P.O. Box 62

Oak Ridge, TN 37831-0062

OSTI http://www.osti.gov

Phone: 865.576.8401

Fax: 865.576.5728

Email: reports@osti.gov

Available for sale to the public, in paper, from:

U.S. Department of Commerce

National Technical Information Service

5301 Shawnee Road

Alexandria, VA 22312

NTIS http://www.ntis.gov

Phone: 800.553 .6847 or 703.605 .6000

Fax: 703.605.6900

Email: orders@ntis.gov 


\section{Acknowledgments}

Support for this work was provided by the U.S. Department of Energy (DOE) Office of Energy Policy and Systems Analysis (EPSA) under the leadership of Kate Marks. We are indebted to Johanna Levene of the National Renewable Energy Laboratory (NREL) for early input on structuring the outputs, and to Josh Bauer of NREL for his graphics work. Municode and the International Code Council (ICC) provided assistance and access to the critical data required to complete the analysis. Finally, we would like to thank the reviewers for their detailed and insightful comments that strengthened this report including Aurora Edington (DOE), Jenny Heeter (NREL), Therese Langer (American Council for an Energy-Efficient Economy [ACEEE]), Jeffrey Logan (NREL), Marguerite Kelly (NREL), Ookie Ma (DOE), Maggie Molina (ACEEE), David Ribeiro (ACEEE), and Paul Schwabe (NREL). Of course, any remaining errors are the responsibility of the authors. 


\section{Executive Summary}

Municipal governments in the United States are well positioned to influence clean energy, including alternative energy, energy efficiency, and sustainable transportation implementation within their jurisdictions through planning, programs, and codification. Municipal governments are leveraging planning processes and programs to shape their energy futures (Aznar et al. 2015). In the literature, understanding of codification - the primary way that municipal governments enact and implement enforceable policies - is more limited.

This report addresses this gap by developing a baseline of municipal codification of certain clean energy-related policies across the United States as of January 1, 2016. This baseline serves as a means to gauge the extent to which municipalities are addressing these policies in their code. To build the baseline, we leverage online databases of municipal codes to develop national and state-specific representative samples of municipalities by population size.

The national sample serves as the basis to understand the scope of alternative energy and sustainable transportation policy codification activity occurring across the country. The statespecific sample offers a means to better understand how municipalities reference alternative energy and sustainable transportation, whether codification varies across the states, whether references are correlated with resource or market potential, and what effect these references might have on markets. This report addresses energy efficiency separately, in part because there is extensive research on the subject. This report adds to the energy efficiency literature with a focus on codified building energy codes.

\section{Establishing the Baseline}

The national findings reveal that:

- Fifty-nine percent of the municipalities in the sample reference at least one clean energy keyword, suggesting that codification of alternative energy and sustainable transportation is widespread across the United States.

- Municipal governments in the sample more often reference alternative energy keywords such as solar, wind energy, and geothermal than sustainable transportation-related keywords.

- Municipalities of all sizes reference solar energy policy more frequently than any other identified alternative energy or sustainable transportation policy. As population size increases, the percentage of municipalities that reference solar increases.

- From a regional perspective, municipalities in the West reference solar, geothermal, and the top three sustainable transportation-related keywords (electric vehicles, alternative fuel, natural gas vehicle/compressed natural gas) more frequently than municipalities in the East, South, or Midwest.

The state-specific sample offers a more granular picture of both the likelihood that municipalities within a state will reference clean energy and how those references differ from state to state. 
- In 31 of the 44 states in the sample, more than $50 \%$ of municipalities reference at least one alternative energy keyword, suggesting that a majority of municipalities are discussing alternative energy in their code.

- The top five states where municipalities reference alternative energy policies on a proportional basis are Delaware, California, Wyoming, Connecticut, and Wisconsin (Figure ES-1).

- Sustainable transportation is most frequently referenced in Washington, Nevada, New Hampshire, Arizona, and California. California is the only state to rank in the top five for code references to both alternative energy and sustainable transportation.

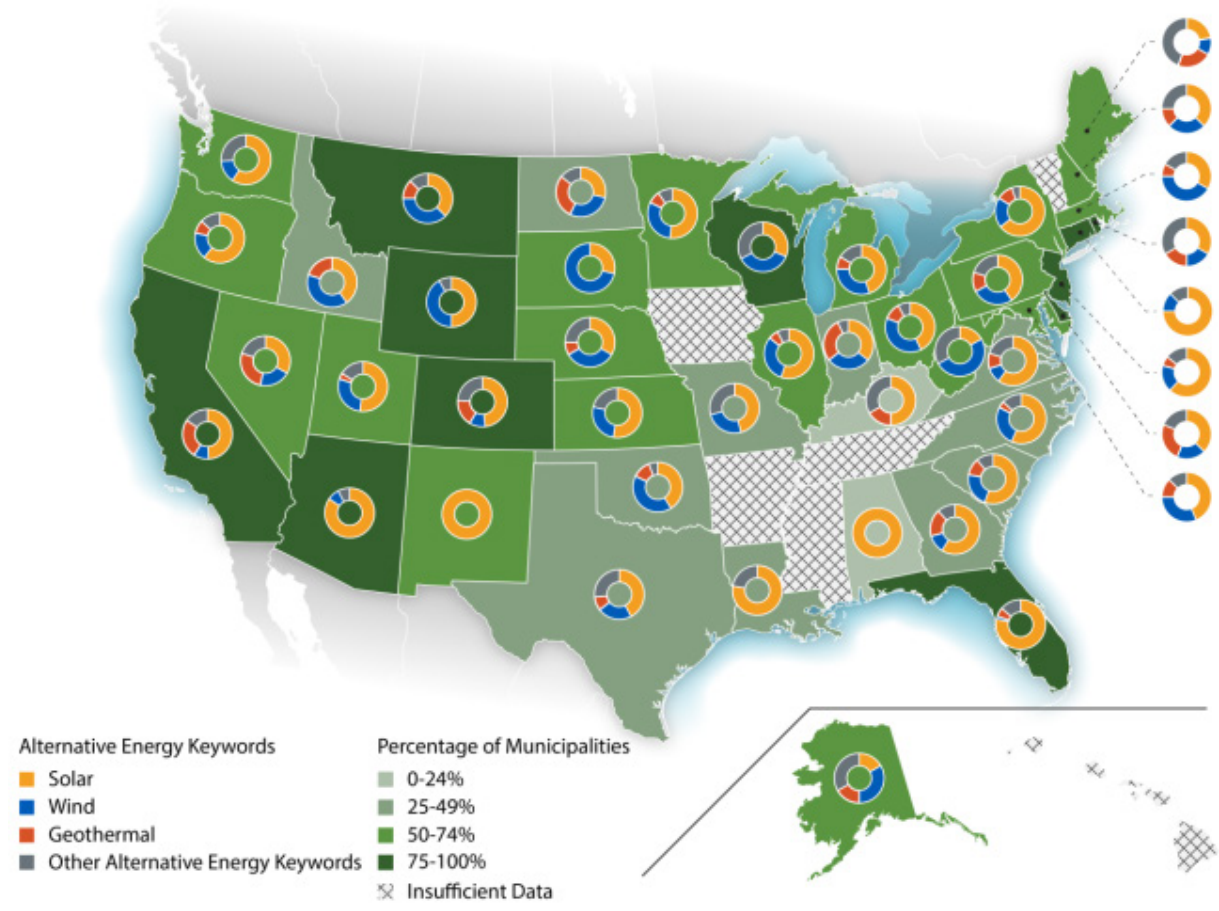

Figure ES-1. Breakdown of alternative energy references by state and proportion of municipalities by state to reference at least one alternative energy keyword

\section{Interpreting the Baseline}

To provide more context as to how jurisdictions are addressing clean energy at the municipal level, analysis was completed across 12 states (based on quantity of references to clean energy) for a subset of the most frequently referenced keywords from the national sample. This "reference analysis" focused on the content and potential impact of the top three search keywords across a subset of states. The keywords include solar (California, Florida, Maryland, and Minnesota), wind energy (Illinois, New Hampshire, Ohio, and South Dakota), and geothermal (Colorado, Delaware, Nevada, and Pennsylvania). The results of the reference analysis show:

- Across all of the municipalities, the majority of references address solar, wind energy, and geothermal in the context of permitting, zoning, and design and development 
standards. This suggests there is some consistency in how municipalities address these technologies.

- Notably, $49 \%$ of the wind energy references are incorporated into all-encompassing wind energy codes that address zoning, permitting, design, and construction, among other stipulations. A similar trend is not apparent in the solar or geothermal references, suggesting that wind energy references are more homogenous.

- Municipal solar reference percentages appear correlated with solar energy resource potential, particularly across the southwestern United States. This trend is not consistent across the country, and references are not correlated with resource potential for wind energy and geothermal.

With access to installed solar photovoltaic (PV) capacity data at the municipal level across six states (Arizona, Georgia, Massachusetts, Minnesota, New York, and New Jersey) it was possible to evaluate whether references to solar within municipal code are correlated with higher installed PV capacity. The results of this analysis demonstrate:

- A correlation may exist between substantively referencing solar within a municipal code and increased installed solar capacity measured in both an aggregate and watts-per-capita basis (Figure ES-2). Lack of municipal-level installed capacity data prevented testing this finding for wind energy or geothermal.

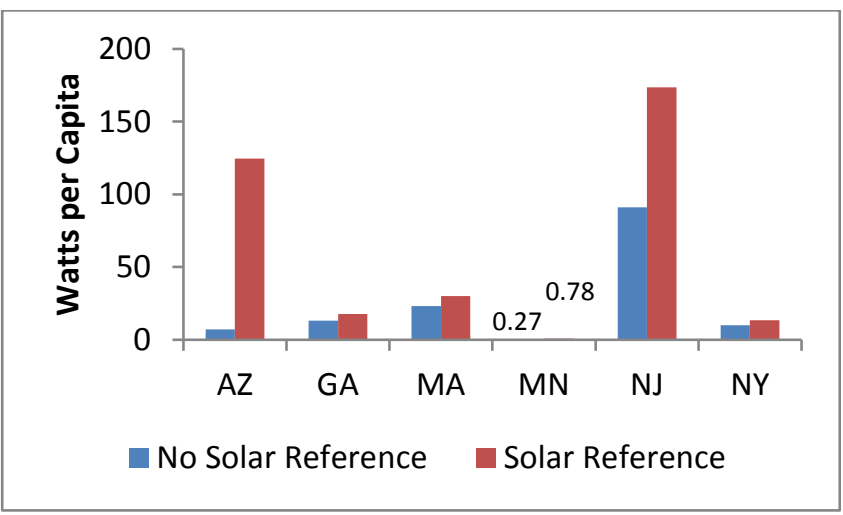

Figure ES-2. Average installed solar PV Watts per capita for municipalities across select states by substantive solar reference

\section{Energy Efficiency: Building Codes Baseline}

To begin to understand how municipalities use codification to address energy efficiency, we focus on residential building energy code adoption. Our analysis finds that at least some municipal governments with the authority to set residential building energy codes within their jurisdictions exercise that authority across states. In some cases, communities set codes higher than their respective state governments (Figure ES-3). 


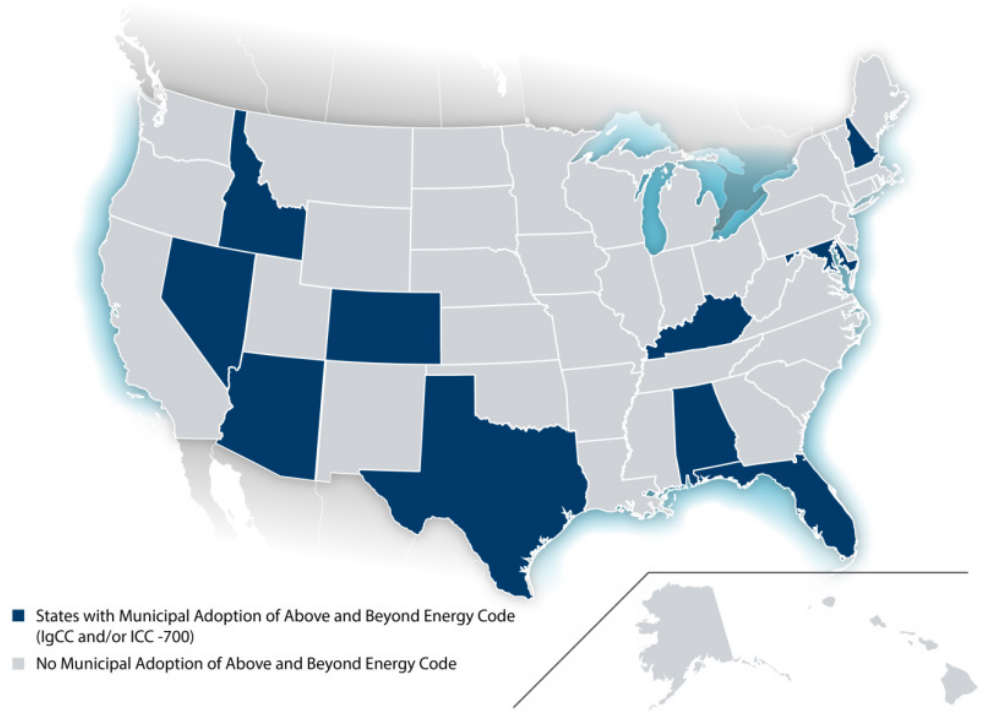

Figure ES-3. Municipal leadership in residential energy code adoption

This examination of codes across the nation indicates that municipal governments are employing their code as a policy mechanism to address clean energy. Future research could clarify the specific relationships between municipal codification and clean energy, particularly as it relates to market development. An example of this could be to further explore the finding that $49 \%$ of wind references in the state specific-sample are within a unified "wind energy code," which could be reflective of technology or market maturity and could lead to insights for other technologies that relate to pathways toward market maturity through codification. 


\section{Table of Contents}

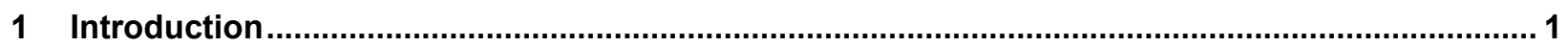

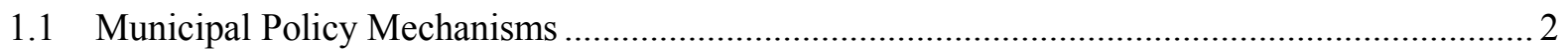

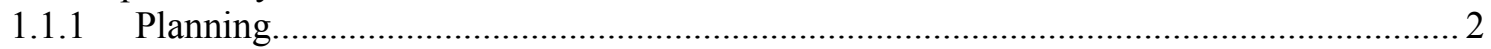

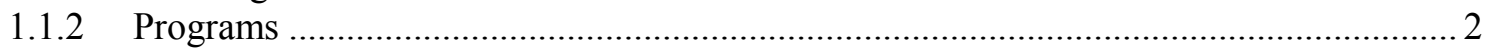

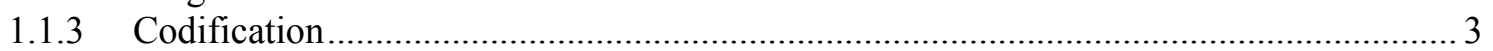

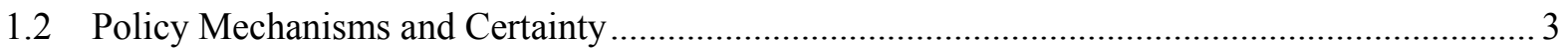

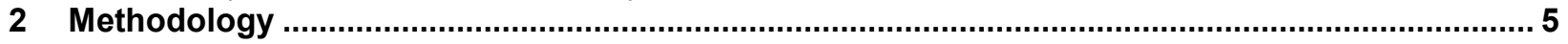

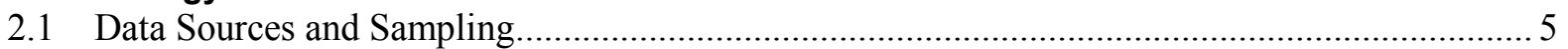

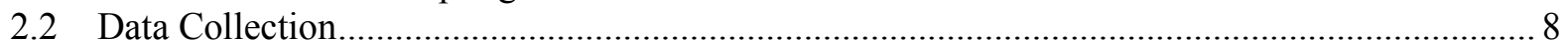

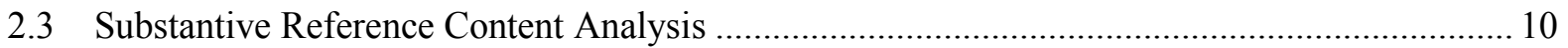

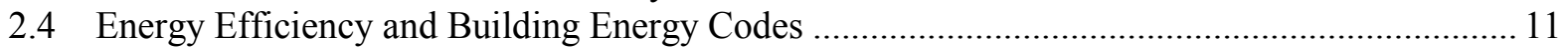

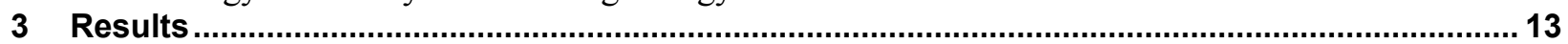

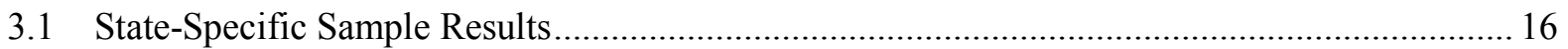

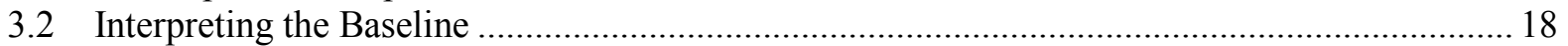

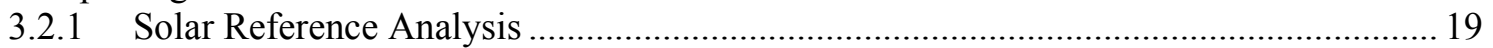

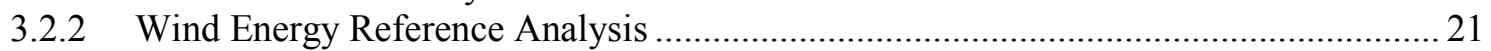

3.2.3 Geothermal Reference Analysis......................................................................... 24

3.3 The Relationship Between Clean Energy References and Market Penetration.......................... 26

3.4 Energy Efficiency and Building Energy Codes ................................................................ 27

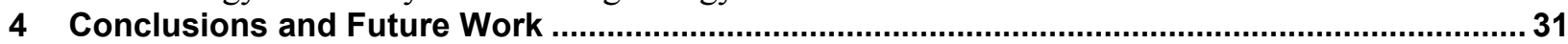

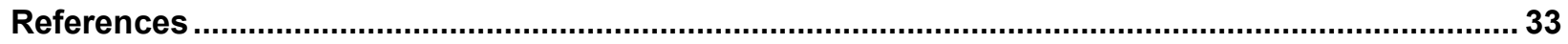




\section{List of Figures}

Figure ES-1. Breakdown of alternative energy references by state and proportion of municipalities by state to reference at least one alternative energy keyword .....................................................

Figure ES-2. Average installed solar PV Watts per capita for municipalities across select states by

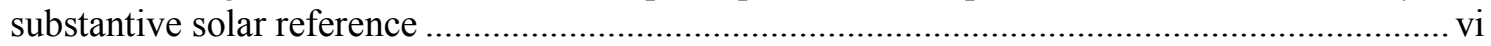

Figure ES-3. Municipal leadership in residential energy code adoption........................................... vii

Figure 1. Mechanisms associated with municipal governments' policymaking .................................. 4

Figure 2. Sample for municipal code clean energy and transportation keyword analysis.................... 8

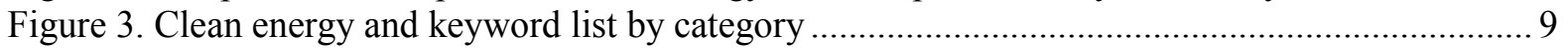

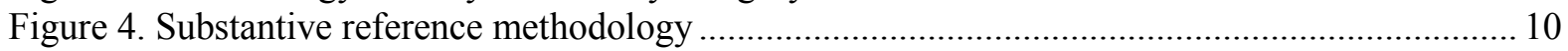

Figure 5. Percentage of municipalities in the sample by total substantive keywords referenced......... 13

Figure 6. Percentage of total references by keyword category and selected terms ............................ 13

Figure 7. Percentage of municipalities by region that reference select alternative energy keywords .. 14

Figure 8 . Percentage of municipalities by region that reference select sustainable

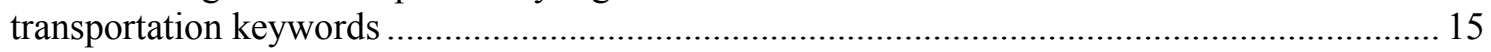

Figure 9. Alternative energy keyword references by municipality population size …........................ 15

Figure 10. Sustainable transportation keyword references by municipality population size ............... 16

Figure 11. Breakdown of alternative energy references by state and proportion of municipalities by state to reference at least one alternative energy keyword .................................................... 17

Figure 12. Breakdown of sustainable transportation references by state and proportion of municipalities by state to reference at least one transportation keyword .................................. 18

Figure 13. Percentage of municipal codes by state that reference the keyword solar ......................... 19

Figure 14. Unique substantive solar references by policy category …............................................. 20

Figure 15. Percentage of municipal codes by state that reference the keyword wind energy .............. 22

Figure 16. Unique substantive wind energy references by category ................................................. 23

Figure 17. Percentage of municipal codes by state that reference the keyword geothermal ................ 24

Figure 18. Unique substantive geothermal references by category .................................................. 25

Figure 19. Average installed solar PV Watts per capita for municipalities across select states by

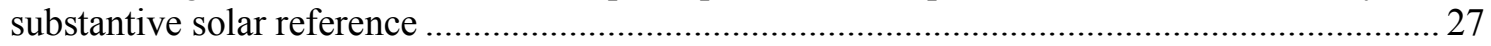

Figure 20. Municipal adoption rates of IECC building energy codes by state ${ }^{\mathrm{a}}$.............................. 28

Figure 21. Municipal leadership in residential energy code adoption................................................ 29

\section{List of Tables}

Table 1. Comparison of Municipalities by Population Size in the United States to those in Municode Database

Table 2. Comparison of Municipalities by Population Size in the United States to those in National Sample

Table A-1. Total Municipalities by State and those Selected for National and State-Specific

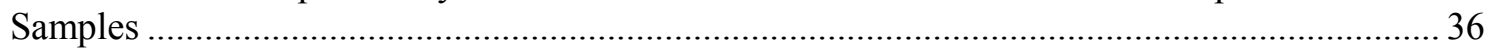

Table B-1. Clean Energy Keywords Considered but not included in this Analysis........................... 38 


\section{Introduction}

The energy footprint of municipalities is significant, as cities ${ }^{1}$ account for $70 \%$ of worldwide energy consumption (Seto and Dhakal 2014). Given that $60 \%$ of the global population is expected to reside in cities by 2030 (Seto and Dhakal 2014), municipal-level energy consumption may grow even more consequential. ${ }^{2}$ Municipalities in the United States have followed this global urbanization trend (United States Census Bureau, 2012) and these governments have the authority to govern functions such as land use, transportation, and building development that directly impact energy use within their jurisdictions (Coenen and Menkveld 2002, 107-125). Municipal governments are thus uniquely positioned to influence future energy consumption.

Municipalities in the United States have exercised this authority to incentivize the development of clean energy within their jurisdiction. For example, Martinot et al. (2011) documented a wide variety of municipal alternative energy policies and programs adopted by 38 municipalities across the country. More recently, Ribeiro et al. (2015) documented and ranked the energy efficiency policies employed by 51 cities, demonstrating the impact of energy efficiency policy adoption on energy savings. Finally, as of January 1, 2016, the Database of State Incentives for Renewables and Efficiency (DSIRE) includes 229 local government policies that address clean energy. ${ }^{3}$ Tracking local policy is not the stated mission of DSIRE, which suggests that these data may capture only a portion of the activity occurring across municipal governments.

There are limitations to the ability of municipal governments to control their energy future. First, municipal governments must operate within the confines of federal and state law. This is apparent in the clean energy space, as federal and state energy policy frameworks, along with financial and technical support, influence local clean energy decision making (Busche 2010; Martinot et al. 2011; Riahi 2015; Steinhoff and Wei 2015). Second, many municipalities do not control the resource mix used in their electricity supply, making it difficult to shift toward renewable and cleaner electricity generation. ${ }^{4}$ Third, depending on the governance structure of the state in which they are located, municipal governments have varying levels of jurisdictional authority to apply to policymaking. "Home rule" states grant local governments significant decision-making authority while "Dillon's Rule" states grant more limited authority (Stout 2014). ${ }^{5}$ A municipality within a Dillon's Rule state is not precluded from addressing clean

\footnotetext{
${ }^{1}$ The terms municipality and city are used interchangeably in this report. The United States Census Bureau defines a municipality as a political subdivision "within which a municipal corporation has been established to provide general local government for a specific population concentration in a defined area, and includes all active government units officially designated as cities, boroughs (except in Alaska), towns (except in the six New England states, and in Minnesota, New York, and Wisconsin), and villages. This concept corresponds generally to the "incorporated places" that are recognized in Census Bureau reporting of population and housing statistics, subject to an important qualification--the count of municipal governments in this report excludes places that are currently governmentally inactive" (US Census Bureau, 2016b).

${ }^{2}$ Currently, $54 \%$ of the world's population lives in cities. See: "World's population increasingly urban with more than half living in urban areas," United Nations, accessed May 10, 2016, http://www.un.org/en/development/desa/news/population/world-urbanization-prospects-2014.html.

3 "Database of State Incentives for Renewables and Efficiency," North Carolina Clean Energy Technology Center, accessed February 12, 2016, http://www.dsireusa.org/.

${ }^{4}$ Municipalities that also provide utility services may have more ability to influence the electricity mix.

${ }^{5}$ Municipalities within 40 states govern under some version of Dillon's Rule, while municipalities within 10 states including Alaska, Iowa, Massachusetts, Montana, New Jersey, New Mexico, Ohio, Oregon, South Carolina, and
} 
energy policy (Stout 2014), but this authority may be more limited than it is for a municipality in a home rule state. Further, home rule and Dillon's Rule classifications vary not only across states but also within topic areas within the same state. That is, the same locality may have varying jurisdictional authority over energy efficiency, transportation, or electricity generation, further complicating the challenge for municipalities to impact local clean energy markets.

\subsection{Municipal Policy Mechanisms}

Despite the limitations described above, local policymakers do influence clean energy policy within their jurisdictions. Interested local policymakers have a range of tools available to them to achieve policy goals, and three of the more common mechanisms include planning, programs, and codification. ${ }^{6}$

\subsubsection{Planning}

Energy, sustainability, and comprehensive plans are all means by which municipalities address clean energy policy. These plans set a vision for the community and can include action steps to achieve that vision. Often, clean energy policies have been an integral component of these plans. Municipalities are increasingly employing plans to formalize energy policy with support from the U.S. Environmental Protection Agency (EPA), ICLEI - Local Governments for Sustainability, and the U.S. Conference of Mayors among other organizations (Wheeler 2008; U.S. Conference of Mayors 2008).

While energy planning varies widely by city, it tends to address similar broad categories, such as buildings, transportation, land use, alternative energy, and waste (Aznar et al. 2015; Erikson et al. 2013). Over time, local clean energy planning has become more prevalent and better understood (Wheeler 2008, Busche 2010, Tang et al. 2010; Bassett and Shandas 2010; Martinot et al. 2011; Svara et al. 2011; Erikson et al. 2013; Aznar et al. 2015). Most recently, Aznar et al. (2015) concluded many cities are using planning processes to address clean energy markets, but quantifying progress and associated impacts is difficult.

\subsubsection{Programs}

Beyond planning, local governments have addressed clean energy programmatically. Energy efficiency, sustainable transportation, and recycling are just a few examples of the topics that local programs and initiatives address. Case study literature captures the variety of these energyrelated programs (Svara et al. 2011; U.S. Conference of Mayors 2008), as do surveys of local governments conducted by groups such as the International City/County Management Association (ICMA), the American Council for an Energy-Efficient Economy (ACEEE), and the U.S. Conference of Mayors (ICMA 2010; U.S. Conference of Mayors 2011; Mackres et al. 2013; Ribeiro et al. 2015).

Utah govern under home rule. See "Local Government Authority,” National League of Cities, accessed April 22, 2016, http://www.nlc.org/build-skills-and-networks/resources/cities-101/city-powers/local-government-authority. ${ }^{6}$ Although they are not a policy mechanism, and they are not specifically discussed in this paper, local energy champions (e.g., mayors or city councilmembers) do exist to promote clean energy policy and they been anecdotally connected to impacts on local policy existence and effectiveness (Hirshfield and Iyer 2012; Salon, Murphy, and Sciara 2014; Steinhoff and Wei 2015; Aznar et al. 2015). 
Despite evidence of local energy programming, Aznar et al. (2015) report that inconsistent funding, insufficient staff capacity, and changing political priorities can impair the continuity and impact of local clean energy programs.

\subsubsection{Codification}

Municipalities also use codification to enact clean energy policy within their jurisdictions. Federal, state, and local governments all establish codes through "the process of organizing and arranging all legislation of a general and permanent nature into a Code" (Wight 2000). Simply put, once a municipality enacts an ordinance, it is included in that municipality's code and it applies to the entire municipality. Municipal code can change over time according to a jurisdiction's priorities, and "re-codification" is the formal process of changing original codes (Wight 2000).

One clean energy policy area where municipalities have actively used codification is adoption of building and building energy codes. Building codes specify construction, design, and safety standards for building structures. Many local governments have added specific requirements that govern the building envelope; heating, ventilation, and cooling systems; and lighting to reduce the energy footprint of new and existing buildings in both the residential and commercial sectors. ${ }^{7}$

A few other clean energy and transportation-related policy codes have also been studied. For example, Smart Growth America ${ }^{8}$ tracks complete streets ${ }^{9}$ ordinances across the states, the American Planning Association ${ }^{10}$ provides a database of local solar-related policies and zoning codes, and the U.S. Department of Energy's (DOE's) WINDExchange ${ }^{11}$ tracks wind energy ordinances. Though these resources are valuable, there is little literature that examines the proliferation of these and other clean energy codes across the country.

\subsection{Policy Mechanisms and Certainty}

Without an understanding of the extent to which clean energy policy is codified, it is challenging to inform decision makers as to (1) the best strategies for achieving their policy goals and (2) how these mechanisms may interact to increase policy effectiveness. The role of codification may be significant in part because implementation certainty increases from plans to programs to codification as reflected in Figure 1 below.

\footnotetext{
${ }^{7}$ Meres, Ryan. “Do Energy Codes Work?” Accessed April 27, 2016, http://bcap-energy.org/do-energy-codes-work/.

${ }^{8}$ See http://www.smartgrowthamerica.org/documents/best-complete-streets-policies-of-2014.pdf.

${ }^{9}$ Complete streets policies "direct decision-makers to consistently fund, plan for, construct, operate, and maintain community streets to accommodate all anticipated users, including people walking, bicycling, taking public transportation and driving cars and commercial vehicles" (Smart Growth America and National Complete Streets Coalition 2015, pg. 1).

${ }^{10}$ See https://www.planning.org/solar/data/.

${ }^{11} \mathrm{See}$ http://apps2.eere.energy.gov/wind/windexchange/policy/ordinances.asp.
} 


\section{MUNICIPAL MECHANISMS FOR ACHIEVING POLICY GOALS}

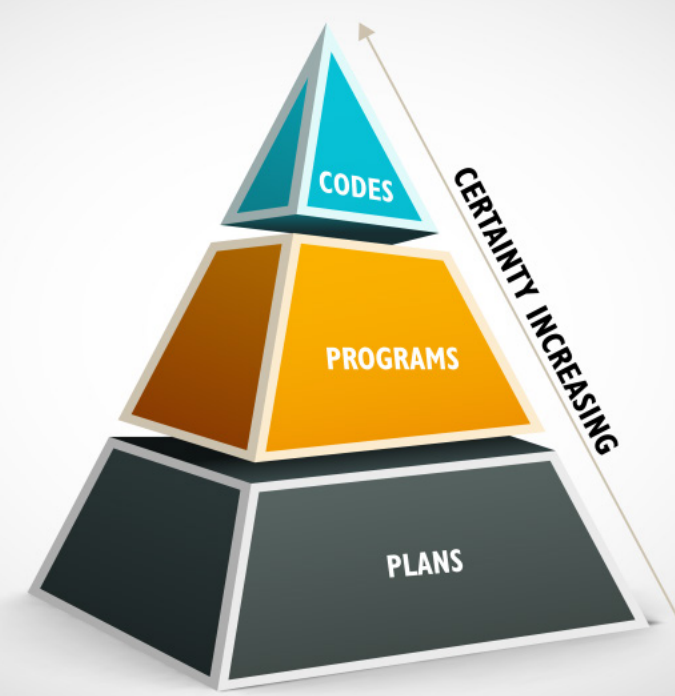

Figure 1. Mechanisms associated with municipal governments' policymaking

Including clean energy policy goals in municipal planning documents can be important in setting the vision and direction of a community. However, many of these plans lack mandated benchmarks and enforcement mechanisms. Programs generally depend on voluntary participation and are often limited to a specific timeframe. On the other hand, policy codification carries the effect of law. Thus, codified policy carries the most policy goal achievement certainty of these three mechanisms.

While codification offers the most certainty, the literature indicates it has received the least empirical attention. The goal of this research is to understand the extent to which codification is a mechanism that local governments are using to influence the development of clean energy within their jurisdictions, and if so, how it is being used. 


\section{Methodology}

To establish a baseline of municipal clean energy codification, we build a $20 \%$ representative sample of municipalities with populations greater than 2,500 at the national and state levels. After developing the sample, we developed a list of keywords for individual municipal code searches for each clean energy category (alternative energy, energy efficiency, and sustainable transportation). The keywords associated with the alternative energy and sustainable transportation categories were searched via online municipal code databases. References were identified for these keywords, and they were initially screened as substantive, non-substantive, or non-applicable and categorized by keyword. In comparison, our analysis of energy efficiency was limited to building energy codes and leveraged International Code Council (ICC) data. Collectively, these data served as the basis to establish national and state level baselines for clean energy codification.

Beyond this initial baseline, we offer some perspective on how municipalities address the three most frequent keywords: solar, wind energy, and geothermal. This was done by completing additional reference-by-reference analyses for each of these keywords across a set of states. In the case of solar, the correlation between codification and installed PV capacity was further examined through a limited-capacity-to-reference-analysis. The remainder of this section examines these processes.

\subsection{Data Sources and Sampling}

Increasingly, municipal governments have turned to third-party providers, such as the Municode Corporation and Generalcode for legal publishing, and these providers often populate codes into searchable online databases. ${ }^{12}$ The municipal government codes made available through these and other third-party providers as of January 1, 2016 serve as the foundation for developing the national and state specific samples included in this research. The methods described below were used to obtain a geographically and demographically representative $20 \%$ sample of municipal codes.

The primary code database for this analysis was the Municode Corporation's MuniPRO online database, which includes over 3,100 municipal, township-level, and county-government codes for cities across the United States. ${ }^{13}$ The majority of codes within the database-approximately 2,300 - are associated with municipal governments, which are the focus of this research. The municipalities with codes included in this database represent about $12 \%$ of all municipal governments in the United States.

The Municode database is not representative of the distribution of municipalities in relation to population, as it disproportionately represents cities with larger populations (see Table 1).

\footnotetext{
${ }^{12}$ See Municode. 2016a. Library. https://www.municode.com/library/ and Generalcode. 2016. Online eCode360 Library. http://www.generalcode.com/codification/ecode/library.

${ }^{13}$ Township, or in some cases, town governments are located in 20 states and are differentiated from municipal governments because they vary widely in the public services they provide (US Census Bureau, 2016a; 2016b). After January 1, 2016 Municode increased its municipal code coverage from 3100 - 4100. See Municode. $2016 \mathrm{~b}$.

Connecting you and your citizens. https://www.municode.com/.
} 
Table 1. Comparison of Municipalities by Population Size in the United States to those in Municode Database

\begin{tabular}{|lllllllll|} 
& $>100,000$ & $\mathbf{5 0 , 0 0 0}$ & $\mathbf{2 5 , 0 0 0}$ & $\mathbf{1 0 , 0 0 0}$ & $\mathbf{5 , 0 0 0}$ & $\mathbf{2 , 5 0 0}$ & $<2,500$ & Total \\
& & - & - & - & - & - & & \\
& & 99,999 & $\mathbf{4 9 , 9 9 9}$ & $\mathbf{2 4 , 9 9 9}$ & $\mathbf{9 , 9 9 9}$ & $\mathbf{4 , 9 9 9}$ & & \\
\hline United & 275 & 433 & 723 & 1,544 & 1,667 & 2,088 & 12,789 & 19,519 \\
States & $(1 \%)$ & $(2 \%)$ & $(4 \%)$ & $(8 \%)$ & $(9 \%)$ & $(11 \%)$ & $(65 \%)$ & \\
\hline Municode & 203 & 200 & 329 & 622 & 456 & 369 & 394 & 2,573 \\
& $(8 \%)$ & $(8 \%)$ & $(13 \%)$ & $(24 \%)$ & $(18 \%)$ & $(14 \%)$ & $(15 \%)$ & \\
\hline
\end{tabular}

Of municipalities in the United States, $65 \%$ have populations below 2,500. Limiting the analysis to cities with populations of 2,500 or greater increases Municode's representation of the remaining municipalities to $32 \%$. Though this is an improvement, it still does not rectify the issue that the Municode data set disproportionately represents larger cities. ${ }^{14}$ In addition to this limitation, the Municode database underrepresents municipalities from certain areas of the country (e.g., the Mid-Atlantic) and over-represents other regions (e.g., the Southeast).

To generate a more representative national sample of cities both geographically and by population, we supplement the Municode data set to generate a 20\% representative sample of municipalities by state and population size category. This study relies on the 2012 census to generate state-by-state $20 \%$ representative samples of municipalities by population category. The 20\% sampling threshold was selected in part because resource constraints required limiting data collection and this rate covers minimum sampling requirements for the purpose of making generalizations (Alreck and Settle, 1995; Irwin et al. 1992).

Within the Municode data set, it was possible to generate representative samples for 16 states by population category. Devising a representative sample for the remaining 34 states required supplementing the Municode data set with cities from other databases. ${ }^{15}$ These other databases, though not as large as Municode, often had more cities than necessary to generate $20 \%$ representative samples for a given state. To reduce potential bias, the cities selected to reach the $20 \%$ representation threshold were randomly selected from alternative databases where available, based on their population size.

\footnotetext{
${ }^{14}$ Initial keyword searches within Municode illustrate that cities with populations greater than 2,500 accounted for $90 \%$ or more of the substantive uses of the keywords (solar, wind energy, and geothermal).

${ }^{15}$ These databases included GeneralCode, http://www.generalcode.com/; Sterling Codifiers, http://www.sterlingcodifiers.com/; Code Publishing Company, http://www.codebook.com/; American Legal Publishing Corporation, http://www.amlegal.com/; and Conway Greene Company, http://www.conwaygreene.com/.
} 
By leveraging other databases, it was possible to generate $20 \%$ representative samples for 41 of the 50 states. Alabama, Connecticut and North Dakota were within four cities of a representative sample and were included in this analysis, but there were insufficient data to develop samples for Arkansas, Hawaii, Iowa, Mississippi, Tennessee, and Vermont. ${ }^{16}$ The final distribution of cities across population categories in the sample is compared to the national distribution in Table 2.

Table 2. Comparison of Municipalities by Population Size in the United States to those in National Sample ${ }^{a}$

\begin{tabular}{|llllllll|} 
& $>100,000$ & $50,000-$ & $\mathbf{2 5 , 0 0 0}-$ & $\mathbf{1 0 , 0 0 0}-$ & $\mathbf{5 , 0 0 0}-$ & $\mathbf{2 , 5 0 0 -}$ & Total \\
\hline United & 275 & 433 & 723 & 1,544 & 1,667 & 2,088 & 6,730 \\
States & $(4 \%)$ & $(6 \%)$ & $(11 \%)$ & $(23 \%)$ & $(25 \%)$ & $(31 \%)$ & \\
\hline Sample & 56 & 88 & 142 & 293 & 312 & 375 & 1,266 \\
& $(4 \%)$ & $(7 \%)$ & $(11 \%)$ & $(23 \%)$ & $(25 \%)$ & $(30 \%)$ & \\
\hline
\end{tabular}

a After removing municipalities from Arkansas, Hawaii, lowa, Mississippi, Tennessee, and Vermont (6,336 municipalities), the remaining 1,266 municipalities in the sample represent $20 \%$ of the national total, Slight percentage differences are a result of rounding and the removal of the aforementioned states.

Ten states-Delaware, Maine, Montana, Nevada, New Hampshire, North Dakota, Rhode Island, South Dakota, and Wyoming - have low municipality totals. For these states, a 20\% sample correlates with as few as two cities (e.g., Rhode Island). This is acceptable for the national analyses because of the low municipality totals of these states in relation to others.

Retaining these low sampling totals for the state-specific analyses related to the prevalence of keywords is problematic from a generalization perspective. Thus, any municipalities that would exceed the $20 \%$ sample within these states that were also available in the Municode data set were added to the particular state's sample for assessing state specific mentions by keyword. ${ }^{17}$ Figure 2 depicts the states in the sample, those with adjusted samples, and those that are excluded. Table A-1 in Appendix A lists the total numbers of municipalities in each sample by state.

\footnotetext{
${ }^{16}$ These states were included in part because there were sufficient additional cities in the nearest population category to serve as replacements. The remaining states had significant gaps in municipal codes available in online databases, making it difficult to generate representative samples.

${ }^{17}$ This increased the municipality sample size from 1,266 to 1,301 .
} 


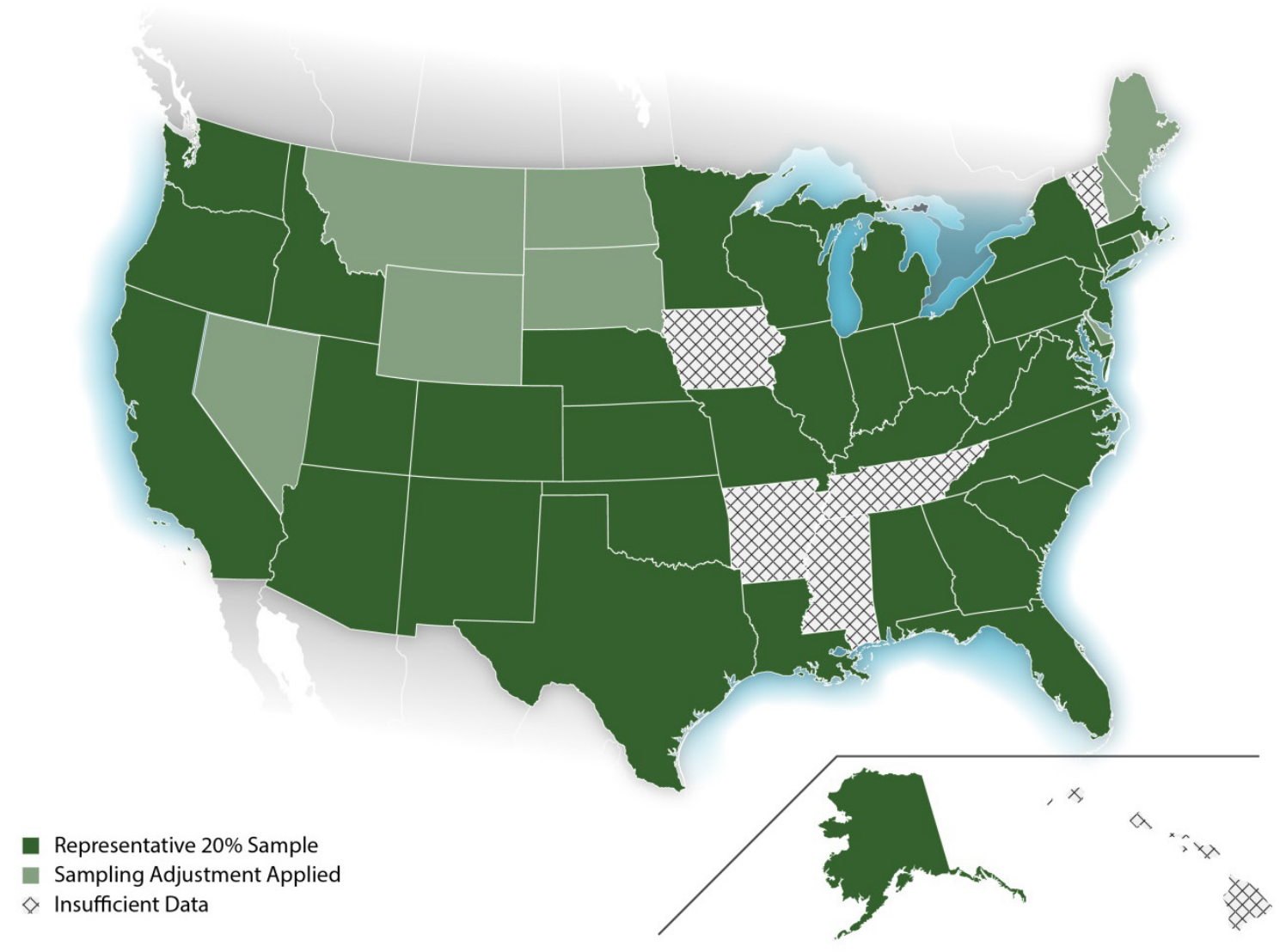

Figure 2. Sample for municipal code clean energy and transportation keyword analysis

\subsection{Data Collection}

After generating the list of municipalities by state, the data collection process for a list of search terms began. A list of initial keywords related to clean energy generated by the authors was reviewed and supplemented by DOE. The list was iteratively revised throughout the data collection process. Many search terms were eliminated due to lack of substantive representation in the Municode database. The final list of keywords is displayed in Figure 3. A complete list of the keywords that were initially considered but not pursued due to resource constraints or lack of frequent database "hits" are listed in Appendix B Table B-1. 

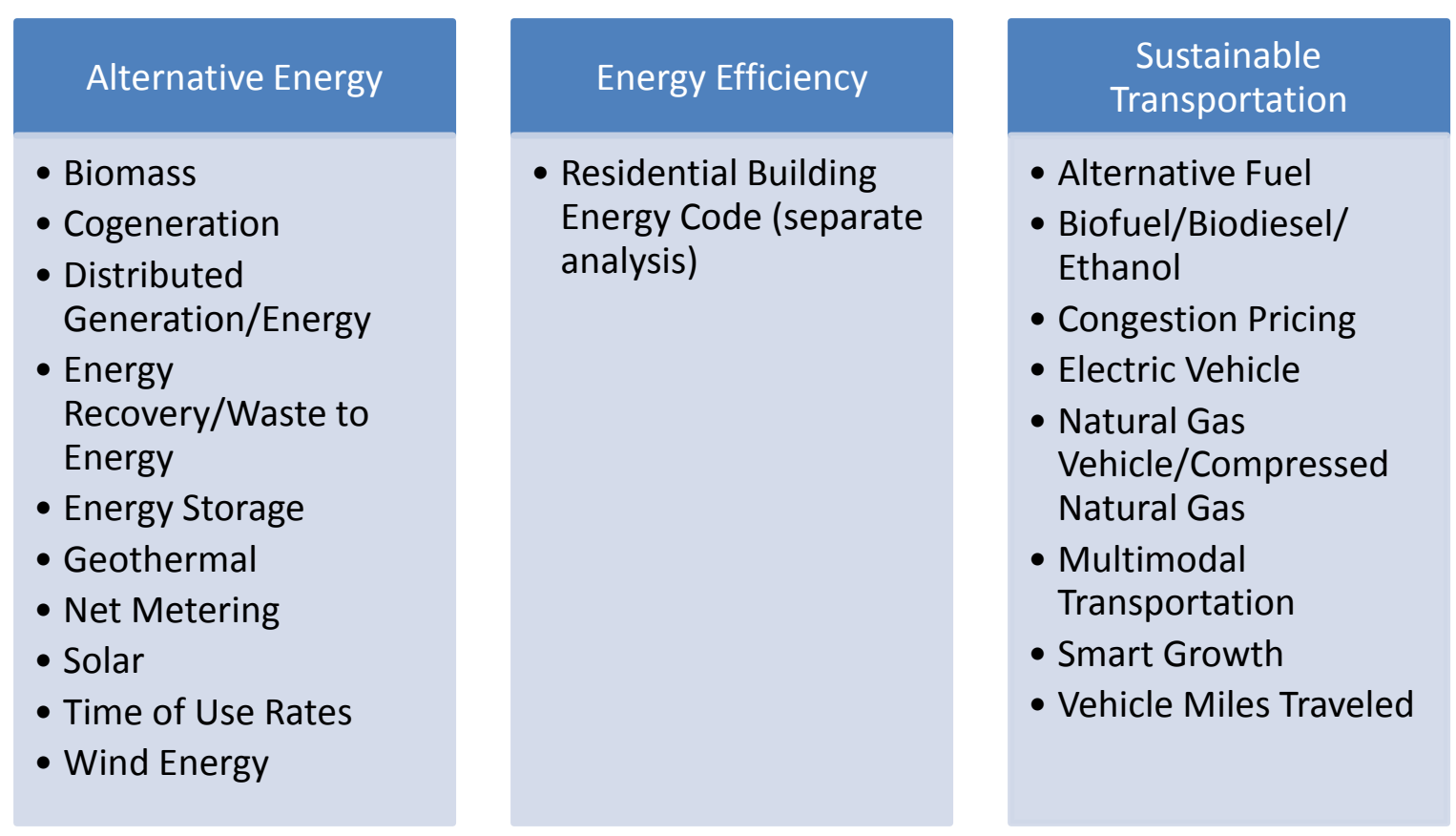

\section{Figure 3. Clean energy and keyword list by category}

Uniform methodology was employed for each keyword. ${ }^{18}$ Each reference, or database hit, found in a keyword search was categorized as a substantive reference, a non-substantive reference, or non-applicable (Figure 4).

A substantive reference is the use of a keyword in a section of code that directly allows, prohibits, or otherwise regulates that specific keyword. ${ }^{19}$ A non-substantive reference is a use of a keyword in an intent, goal, purpose, or definition section of a code. ${ }^{20}$ For these references, if the term is used elsewhere in a substantive manner, it is considered a substantive reference. For example, if the solar keyword was used in the definition of alternative energy, and the term alternative energy was later mentioned as an applicable use in a specified zoning district, that municipality was considered to have substantively referenced solar. Similarly, for those keywords included in a non-substantive intent, goal, or purpose section, if subsequent language or sections of the code substantively addressed the given keyword, the reference was also categorized as substantive.

Finally, a reference was considered non-applicable if the use of the term was not related to energy efficiency, alternative energy, or transportation. Non-applicable references were most common when searching for the term "solar." For example, references to the "solar time of day" were considered non-applicable.

\footnotetext{
${ }^{18}$ With the exception of the building codes analysis, the data collection methodology for this term is discussed in Section 2.4.

${ }^{19}$ Though this baseline includes policy that may not incentivize clean energy policy, the vast majority of references reviewed in this report were market neutral or supporting, as opposed to market barriers suggesting that the quantity of references limiting clean energy is low.

${ }^{20}$ References to applicable state statute were also considered non-substantive for this research because these references reflect existing state law and not policy unique to a municipality.
} 
If a non-substantive or non-applicable reference was found for a particular municipality, further references were reviewed until a substantive reference was identified or it was determined that the municipality had no substantive references to the keyword. As such, this initial analysis describes whether a municipality references a certain keyword but not how many times or in how many different sections of code.

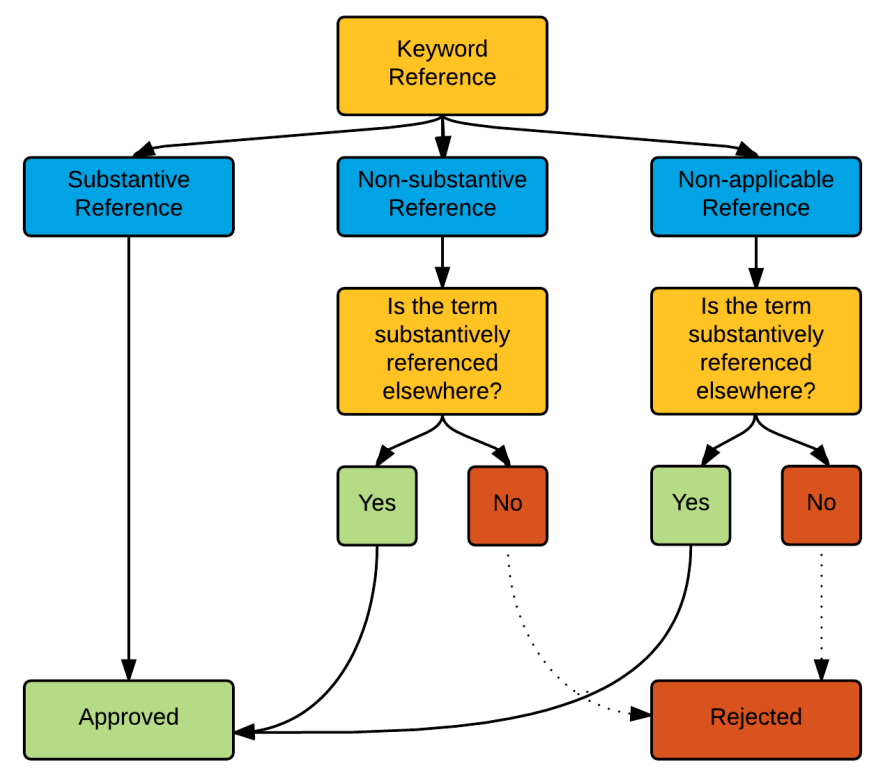

Figure 4. Substantive reference methodology

\subsection{Substantive Reference Content Analysis}

After determining which municipalities in the national and state-specific samples reference each keyword in a substantive, non-substantive, or non-applicable manner, the number of unique municipalities with substantive references were tallied and compared across states and regions.

This analysis revealed that three keywords—-solar, wind energy, and geothermal—were substantively referenced by $10 \%$ or more municipalities in the state-specific sample. No other term was referenced by more than $5 \%$ of municipalities. Given the significant reference gap between these three terms and the others, these terms were selected for the subsequent reference analysis. The goal of this analysis was to both describe how municipalities are discussing these three alternative energy terms in practice and begin to assess the potential impact of these references. ${ }^{21}$ Given the significant quantity of references associated with solar, wind energy, and geothermal, further subsampling was required to address these questions. A second $20 \%$ sample of the substantive mentions of each of the terms was created. This sample was developed by selecting states that have high percentages of municipalities that reference one of the three keywords and also offer geographic variation. This approach was a useful means to capture potential variations in municipal references within states and across regions, and it offers a more complete understanding of how these terms are referenced by municipalities nationally.

${ }^{21}$ Though this type of formal analysis was not completed for the other keywords, the common themes related to how each term is referenced across the United States are discussed in each keyword's relevant section: Section 3.2.1, 3.2.2, and 3.2.3. 
A total of 587 municipalities within the state-specific sample had substantive references to solar. ${ }^{22}$ Municipalities from four states - California, Florida, Maryland, and Minnesota-were selected to compare solar references. ${ }^{23}$ A total of 273 municipalities reference wind in their municipal code, and municipalities from four states were selected for this analysis: Illinois, New Hampshire, Ohio, and South Dakota. Finally, 125 municipalities substantively reference geothermal in their municipal code and municipalities within Colorado, Delaware, Nevada, and Pennsylvania were selected. ${ }^{24}$ The results of each of these analyses are discussed in Sections 3.2.1-3.2.3.

\subsection{Energy Efficiency and Building Energy Codes}

ACEEE tracks and provides substantive analysis on the wide breadth of policies that municipalities can adopt to influence energy efficiency as discussed in The 2015 City Energy Efficiency Scorecard (Ribeiro, et al. 2015). Building energy code adoption is one of the key components that shape municipal energy efficiency policy, and it is a focus of this report. We seek to establish an understanding of the frequency and trends of municipal building energy code adoption nationwide.

To understand which building codes were adopted at the municipal level, we sourced data from existing industry documentation and in particular the ICC. This approach was preferable to using the online code databases, given the significant quantity of building energy code keyword search hits and the difficulty in discerning most recent code adoptions.

The landscape of building energy code adoption varies by state. Even within a state, cities may elect to adopt energy codes "above and beyond" state energy codes, choosing from a variety of available building energy codes, including ASHRAE's standards for commercial construction and ICC codes that can be applied to either commercial or residential construction. ${ }^{25}$ Examples of ICC codes include the International Energy Conservation Code (IECC), the National Green Building Standard (ICC 700), and the International Green Construction Code (IgCC).

The ICC provided the authors with self-reported code adoption by jurisdiction (including municipalities, counties, and states) and the type of ICC code adopted as of February 2016. This ICC data served as the foundational source for this building code analysis. As ICC codes represent nearly all energy codes adopted for residential construction, but only a portion of commercial energy codes, this data set was best suited for analysis of residential building energy code adoption at the municipal level.

\footnotetext{
22 Results for the solar keyword include references to both solar hot water heaters and PV.

${ }^{23}$ To ensure geographic variation and to maintain population representation within each selected state, the sample for solar references is higher than the others at about $25 \%$

24 The geothermal keyword results include references to both geothermal heating and cooling and electricity generation.

${ }^{25}$ Additional pathways for municipal adoption of advanced energy codes include programs like stretch codes in Massachusetts. See "Stretch Energy Code: Information," Commonwealth of Massachusetts, accessed April 22, 2016, http://www.mass.gov/eopss/consumer-prot-and-bus-lic/license-type/csl/stretch-energy-code-information.html.
} 
The ICC data set was used in combination with state level adoption data from February 2016, as reported by the Building Codes Assistance Project (BCAP). ${ }^{26}$ The levels of jurisdictional adoption by state were tallied across the IECC, IgCC, and ICC 700 codes, as these three codes account for the majority of energy efficiency codification for new residential construction.

Because the ICC data include 535 self-reporting municipalities across 33 states, ${ }^{27}$ the ability to draw definite conclusions is limited. However, trends in municipal residential building energy code adoption emerge from the data and thus serve as a basis for future work in this space. ${ }^{28}$

26 “Code Status: Residential, BCAP, accessed April 22, 2016." http://energycodesocean.org/code-status-residential 27 "International Codes: Adoption by Jurisdiction (February 2016)," ICC, accessed April 22, 2016, http://www.iccsafe.org/wp-content/uploads/jurisdictionadoptions.pdf.

${ }^{28}$ For example, Cort and Butner (2012) do not employ ICC data and instead use a sample of 21 states and gather municipal adoption rates via Regional Energy Efficiency Organizations. Despite the different methods, the general trends of jurisdiction adoption by state are congruent and complimentary between Cort and Butner (2012) and our results. 


\section{Results}

Of the 1,266 municipalities in the national sample, 748 (59\%) substantively reference at least one alternative energy or sustainable transportation-related keyword in their municipal code. In comparison, $30 \%$ of the municipalities reference more than one keyword (Figure 5). Of the 748 municipalities, there were 1,402 substantive mentions of any given keyword. Eighty-four percent of these references address alternative energy keywords, while only $16 \%$ address sustainable transportation keywords. Solar, wind energy, and geothermal account for two of every three keyword references across the sample (see Figure 6).

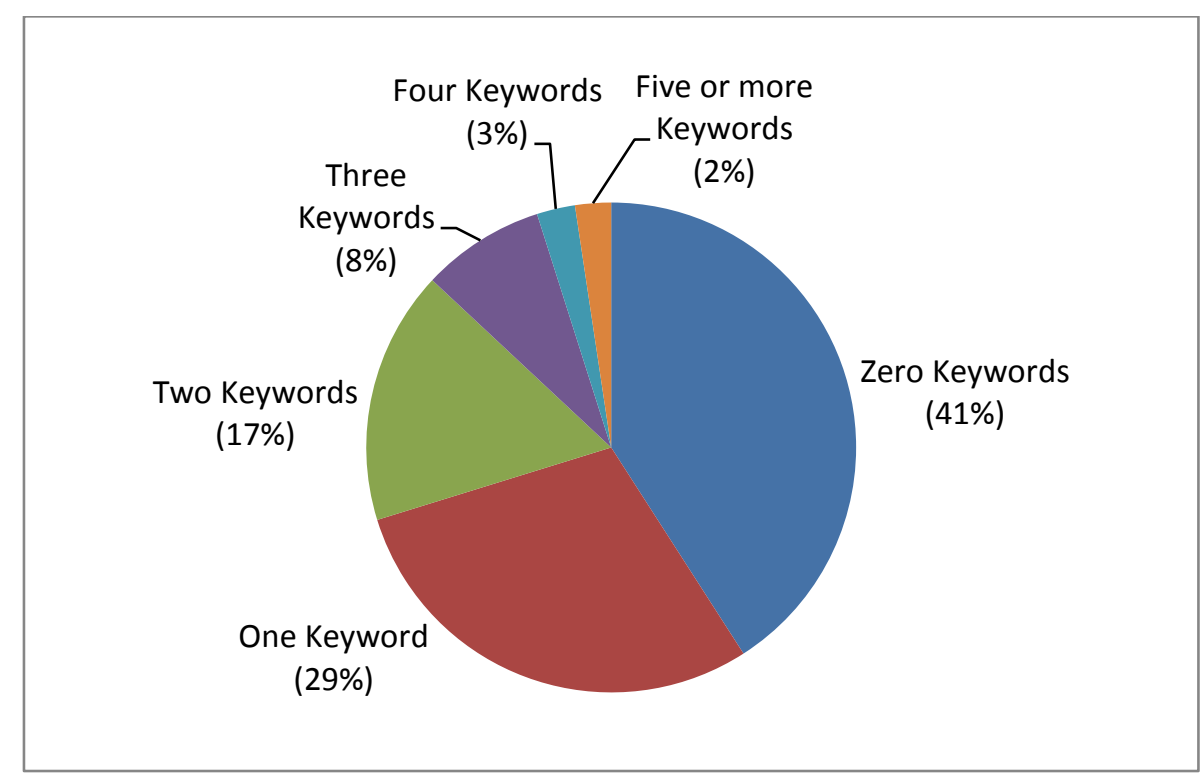

Figure 5. Percentage of municipalities in the sample by total substantive keywords referenced

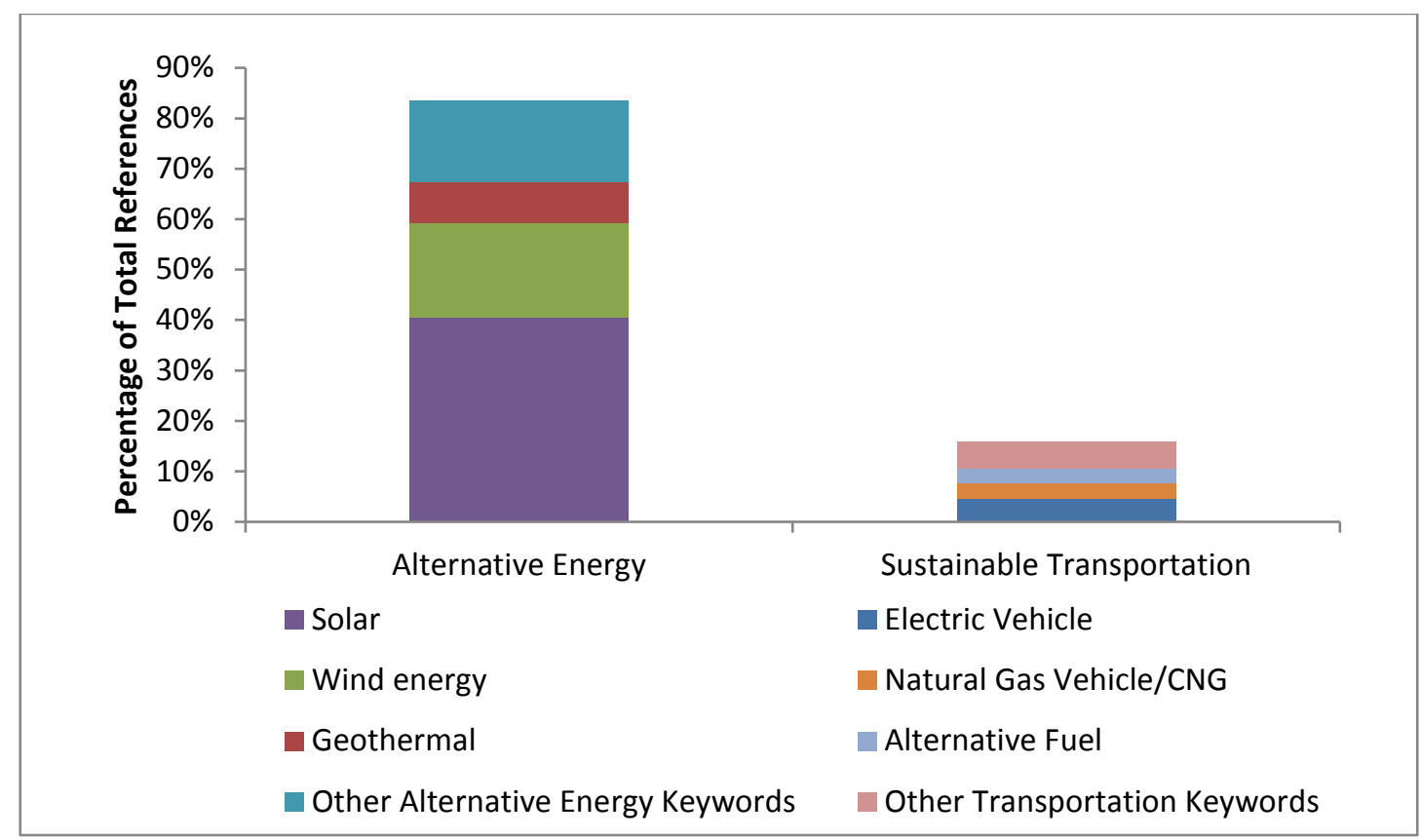

Figure 6. Percentage of total references by keyword category and selected terms 
Though over half of all the municipalities reference at least one keyword, there is regional variation in the keywords referenced. For ease of presentation, the top three alternative energy and sustainable transportation keywords are displayed in Figure 7 and Figure 8 by region respectively. Figure 7 illustrates that solar is the most common alternative energy keyword referenced across all regions, but the percentage of municipalities that reference solar declines from a high of $62 \%$ in the West to $30 \%$ in the South. In comparison, wind energy is most commonly referenced by municipalities within the Midwest, though it still trails solar. References to geothermal are slightly more common than wind energy in the West, but this keyword trails the others in the remaining regions.

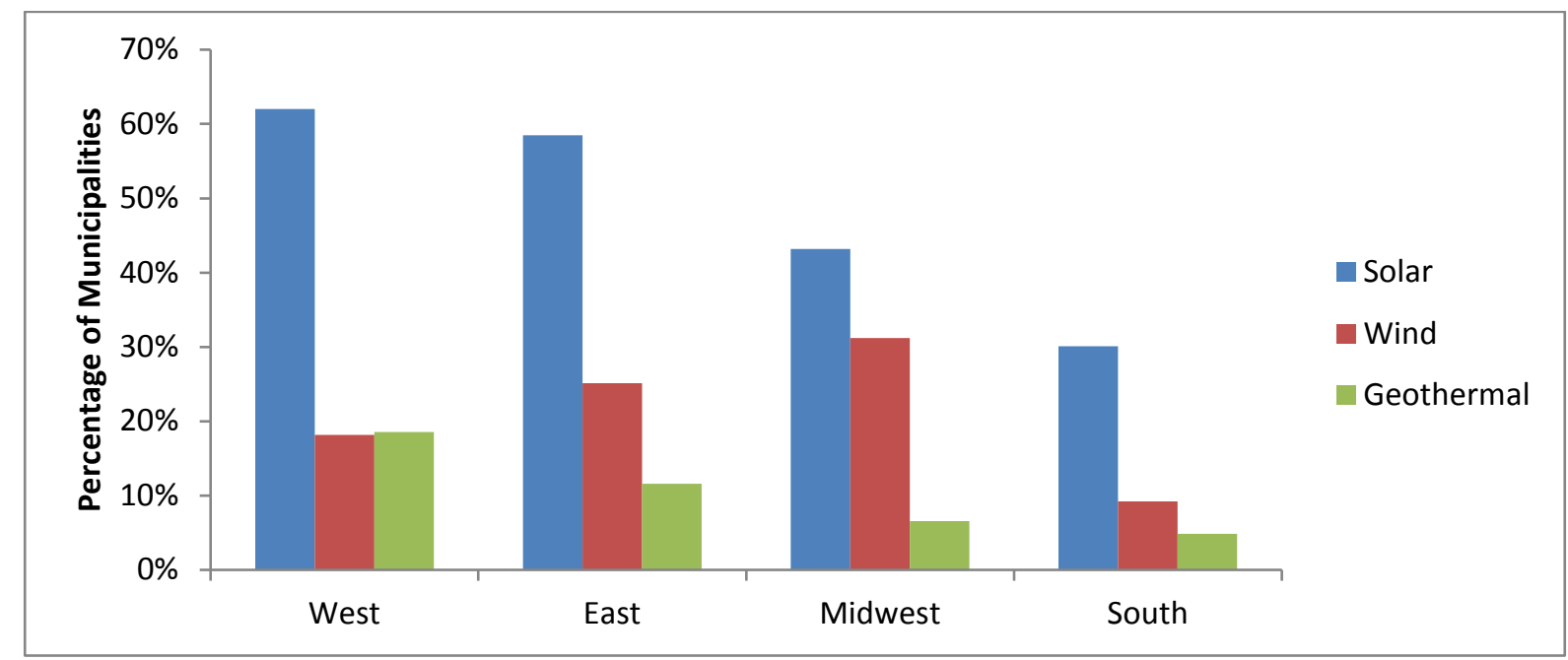

Figure 7. Percentage of municipalities by region that reference select alternative energy keywords

For the three most common sustainable transportation keywords, municipalities in the West more frequently reference all three (electric vehicles, alternative fuel, and natural gas vehicle/compressed natural gas) than municipalities in all other regions (Figure 8). ${ }^{29} \mathrm{In}$ fact, no sustainable transportation keyword was referenced by more than $4 \%$ of cities in any other region.

\footnotetext{
${ }^{29}$ Thirty-three percent of all the transportation-related keyword references are sourced from municipal codes in California and Washington.
} 


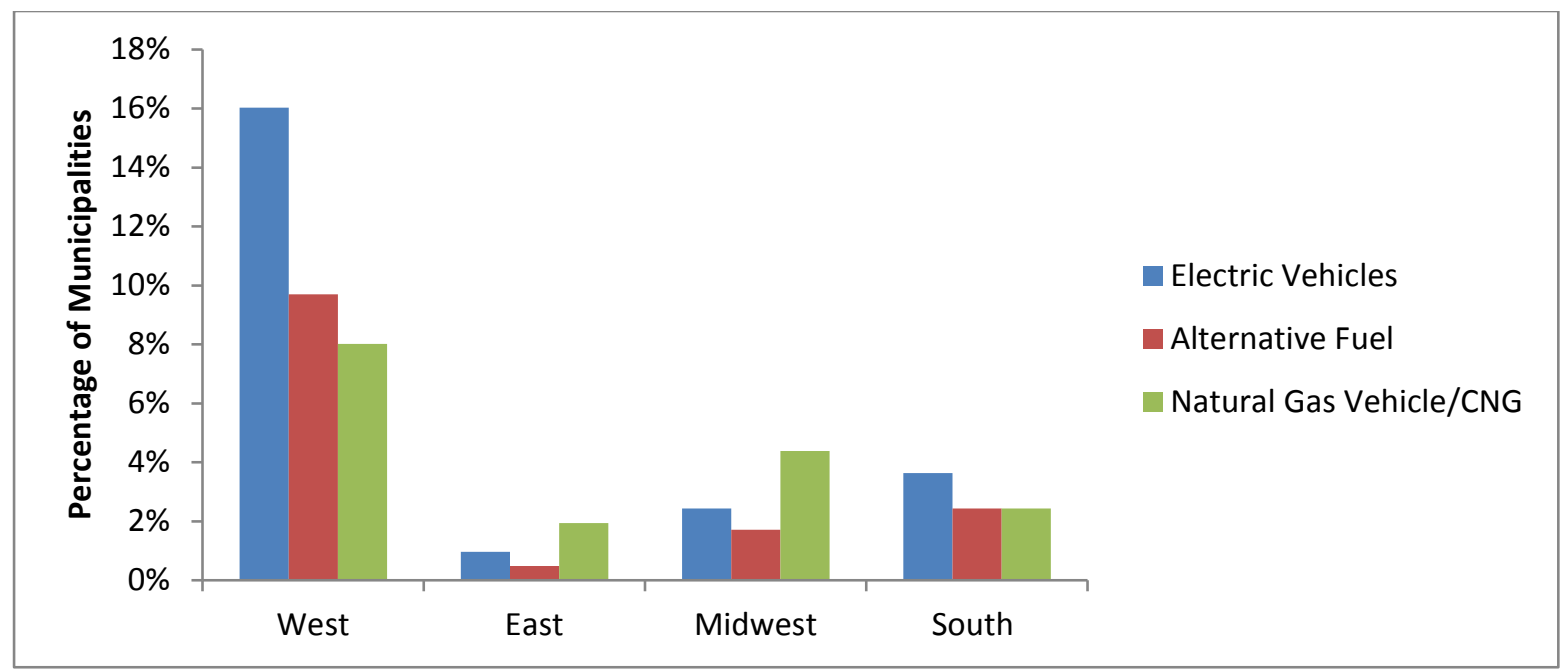

Figure 8. Percentage of municipalities by region that reference select sustainable transportation keywords

Alternative energy codification tends to increase with municipal population size. More than half of municipalities with populations of more than 10,000 substantively mention solar, and this proportion steadily declines as municipal population declines (Figure 9). The municipalities that mention geothermal, though comparatively fewer, follow a similar trend to that of solar, such that larger municipalities are more likely to reference geothermal than smaller ones. In contrast, midsize cities, or those with populations from 25,000 to 49,999 are more likely to reference wind energy than their larger or smaller counterparts.

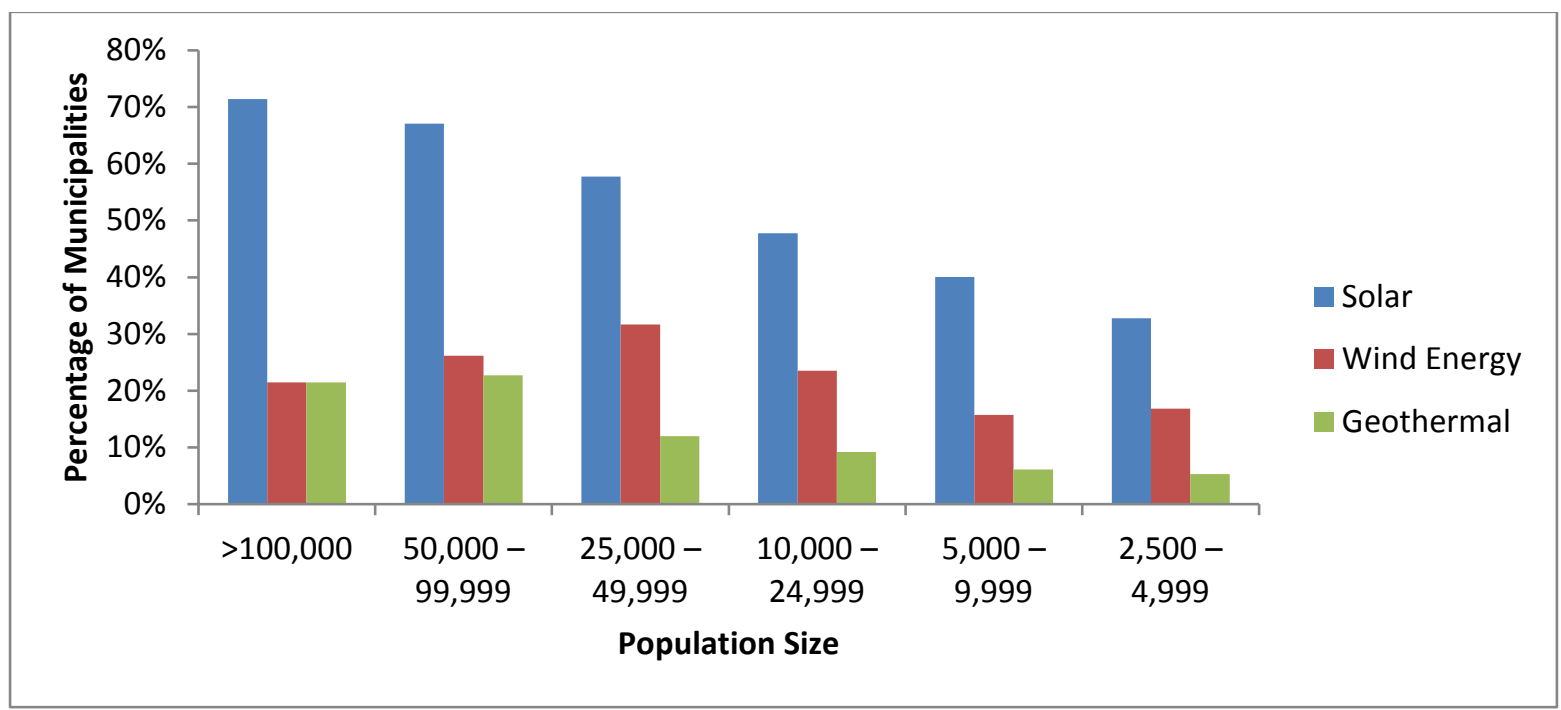

Figure 9. Alternative energy keyword references by municipality population size

Very large cities are also the most likely to reference the three most common sustainable transportation keywords (Figure 10). Smaller cities are more likely to mention electric vehicles than the other keywords, but none of the keywords is referenced by more than $13 \%$ of municipalities with fewer than 100,000 people. 


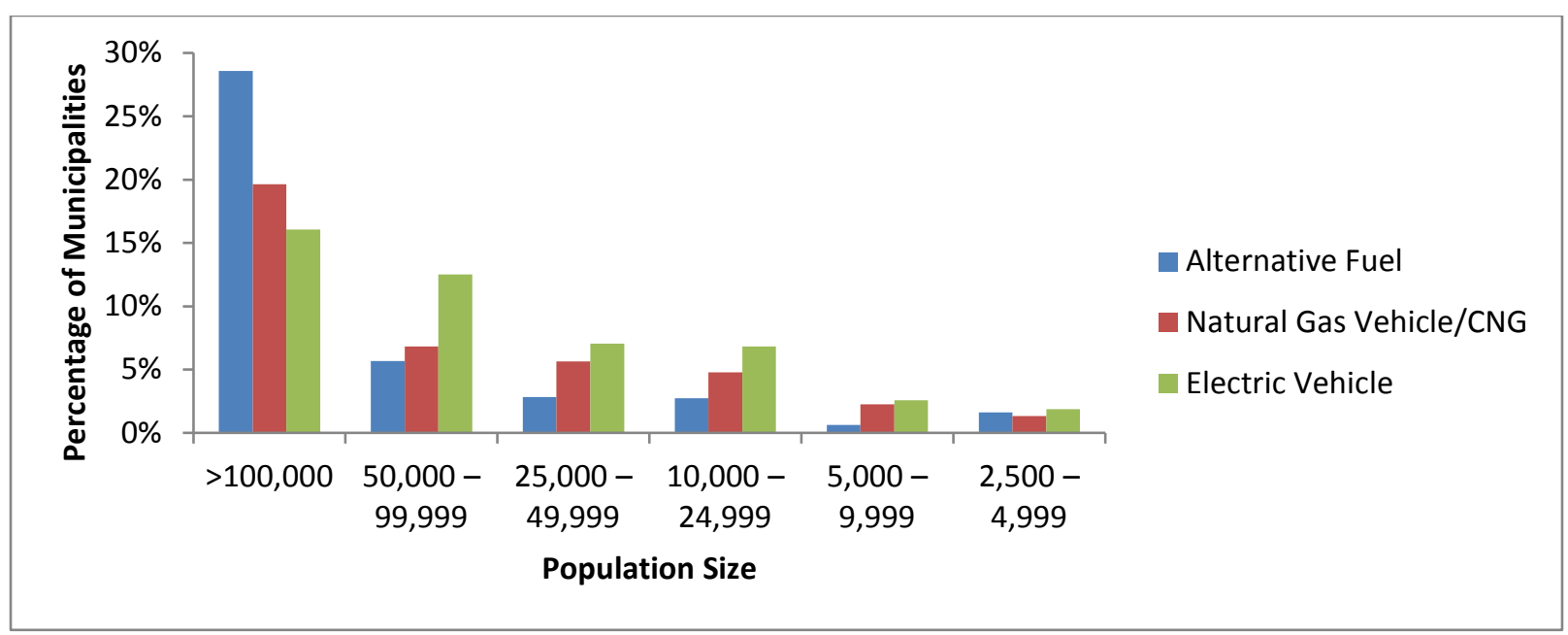

Figure 10. Sustainable transportation keyword references by municipality population size

\subsection{State-Specific Sample Results}

Data in the state-specific sample illustrate the significant variation in both (1) the quantity of municipalities within a given state that reference alternative and sustainable transportation keywords and (2) the variation among the individual keywords referenced. ${ }^{30}$ Figure 11 provides a state-by-state breakdown of all the alternative energy keywords referenced by municipalities, along with the percentage of municipalities that reference at least one alternative energy keyword within each state.

Despite the variation in alternative energy keywords referenced, $50 \%$ or more municipalities across 31 state samples reference at least one alternative energy keyword (Figure 11). This suggests that many municipalities are discussing alternative energy in their code. The top five states based on the percentage of municipalities that mention alternative energy keywords in the sample are Delaware (100\%), California (89\%), Wyoming (89\%), Connecticut (86\%), and Wisconsin (84\%). Solar is the most prevalent keyword across all of the states except Wisconsin, where wind energy references slightly edge out solar and other alternative energy keywords. ${ }^{31}$

\footnotetext{
${ }^{30}$ Here the sample size is increased for those states with lower municipality totals, including Delaware, Maine, Montana, Nevada, New Hampshire, North Dakota, Rhode Island, South Dakota, and Wyoming. This increased the municipality sample size from 1,266 to 1,301 .

${ }^{31}$ In the case of Wisconsin, the most frequently referenced other alternative energy keyword was energy recovery.
} 


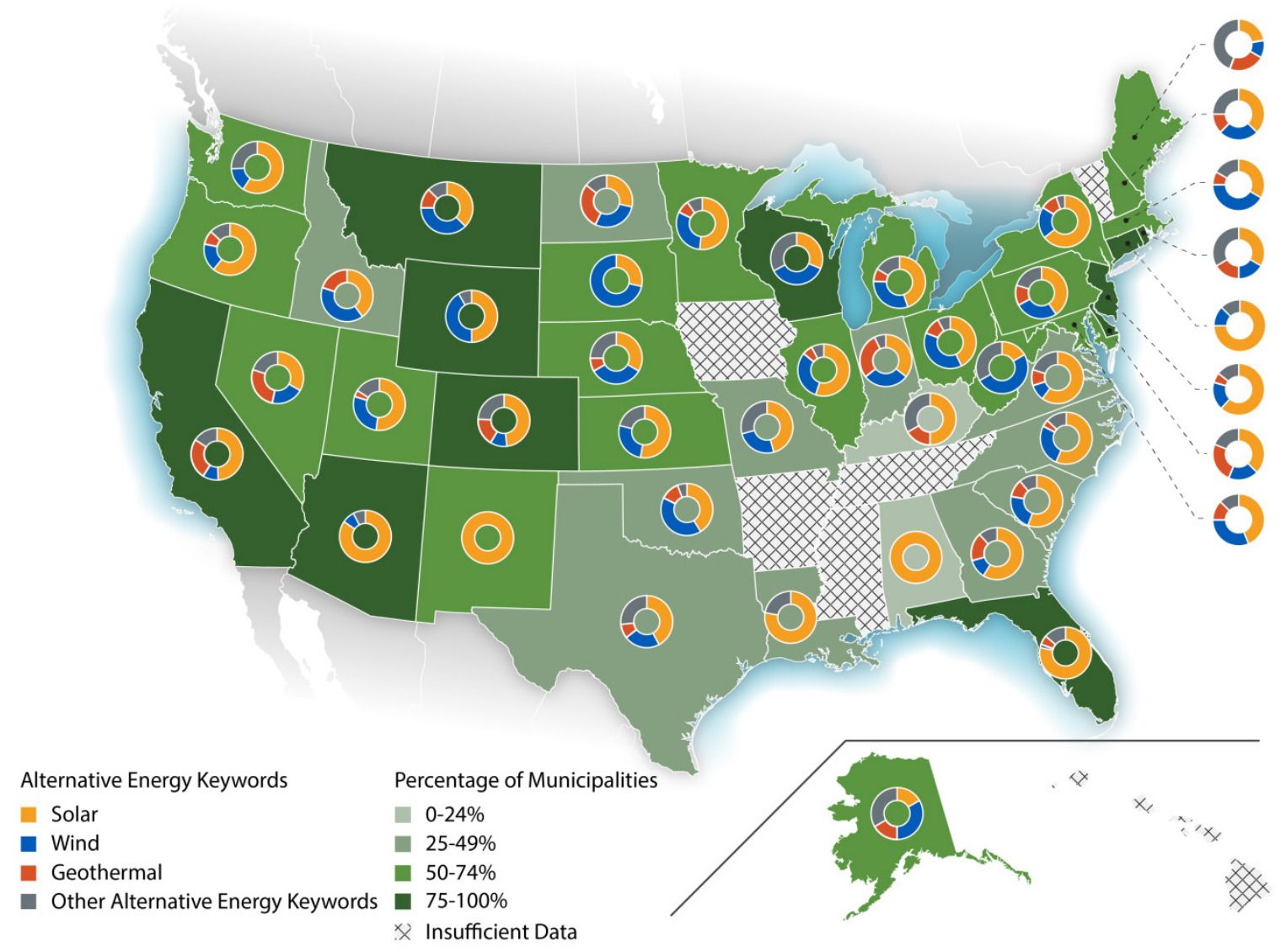

Figure 11. Breakdown of alternative energy references by state and proportion of municipalities by state to reference at least one alternative energy keyword

Figure 12 shows the state-by-state breakdown for the sustainable transportation keywords. Here, $50 \%$ or more municipalities in only two state samples, Washington and Nevada, mention at least one sustainable transportation keyword, which is significantly different than the 31 states for the alternative energy keywords. The top five states where municipalities reference transportation keywords are Washington (55\%), Nevada (50\%), New Hampshire (43\%), Arizona (40\%), and California (40\%). California is the only state to rank in the top five for both keyword categories.

There is more variation in the specific keywords referenced by the top five states. Here, municipalities in Washington and California most frequently reference electric vehicles, municipalities in Arizona and Nevada most commonly reference alternative fuel. And, municipal references in New Hampshire were evenly split between electric vehicles, natural gas vehicle/compressed natural gas $(\mathrm{CNG})$, and other sustainable transportation keywords (Figure 12). 


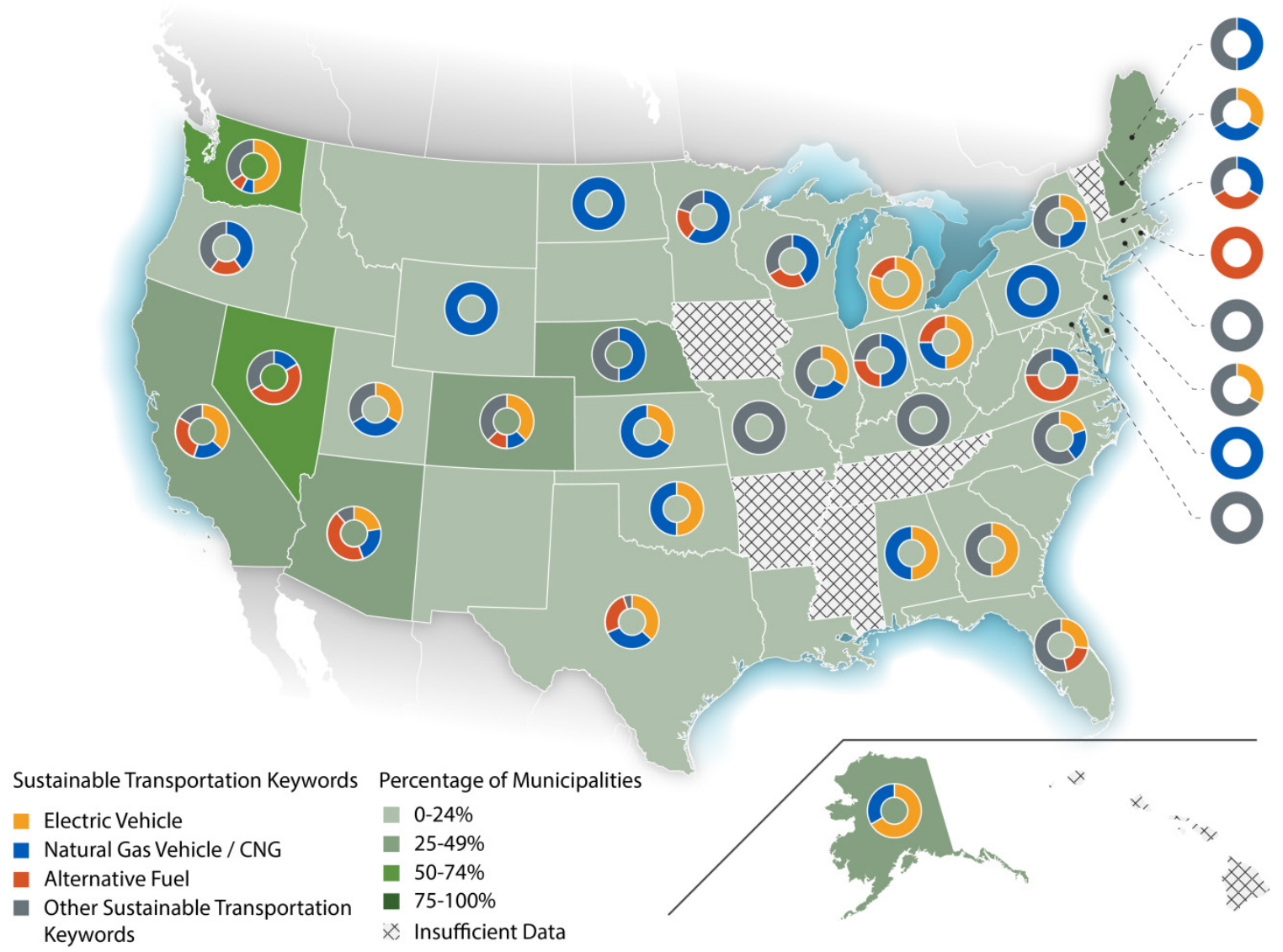

Figure 12. Breakdown of sustainable transportation references by state and proportion of municipalities by state to reference at least one transportation keyword

\subsection{Interpreting the Baseline}

Despite the variation in keyword references, it is clear that solar, wind energy, and geothermal are the most frequently referenced clean energy keywords in both the national and state-specific samples. The following reference analysis results offer some context regarding how municipalities address these three keywords in municipal codes. ${ }^{32}$

\footnotetext{
${ }^{32} \mathrm{We}$ did not conduct a similar detailed analysis for the most frequently referenced sustainable transportation keywords: electric vehicle, natural gas vehicle/CNG, and alternative fuel. However, it is useful to note some of the common themes identified in these references. References to electric vehicles frequently addressed parking requirements, zoning for charging station infrastructure, and to an extent, tax policy. The natural gas vehicle/CNG category included references that either prohibited or limited siting of CNG facilities in certain zones. Others set equipment standards, permitting requirements, and fees for CNG storage facilities or converted vehicles. Finally, references related to the alternative fuel category addressed parking for alternative fuel vehicles, requirements for gas stations that sell traditional and alternative fuels, and requirements for alternative fuel-powered taxicabs (often related to car life regulations), and rentals among others.
} 


\subsubsection{Solar Reference Analysis}

With 587 municipalities or $45 \%$ of the sample referencing solar, it is the most frequently referenced clean energy keyword across the sample. ${ }^{33}$ As noted, not all regions of the country are equally likely to reference solar. The regional variation is clearer in the state-by-state breakdown depicted in Figure 13. Fifty percent or more municipalities in 17 states reference solar; one-quarter to one half of municipalities in 19 states mention solar; and, in eight states, less than one-quarter of municipalities reference solar. The highest concentrations of municipalities that reference solar are located in the Southwest; a finding that is likely related to the significant solar resource in the region. ${ }^{34}$

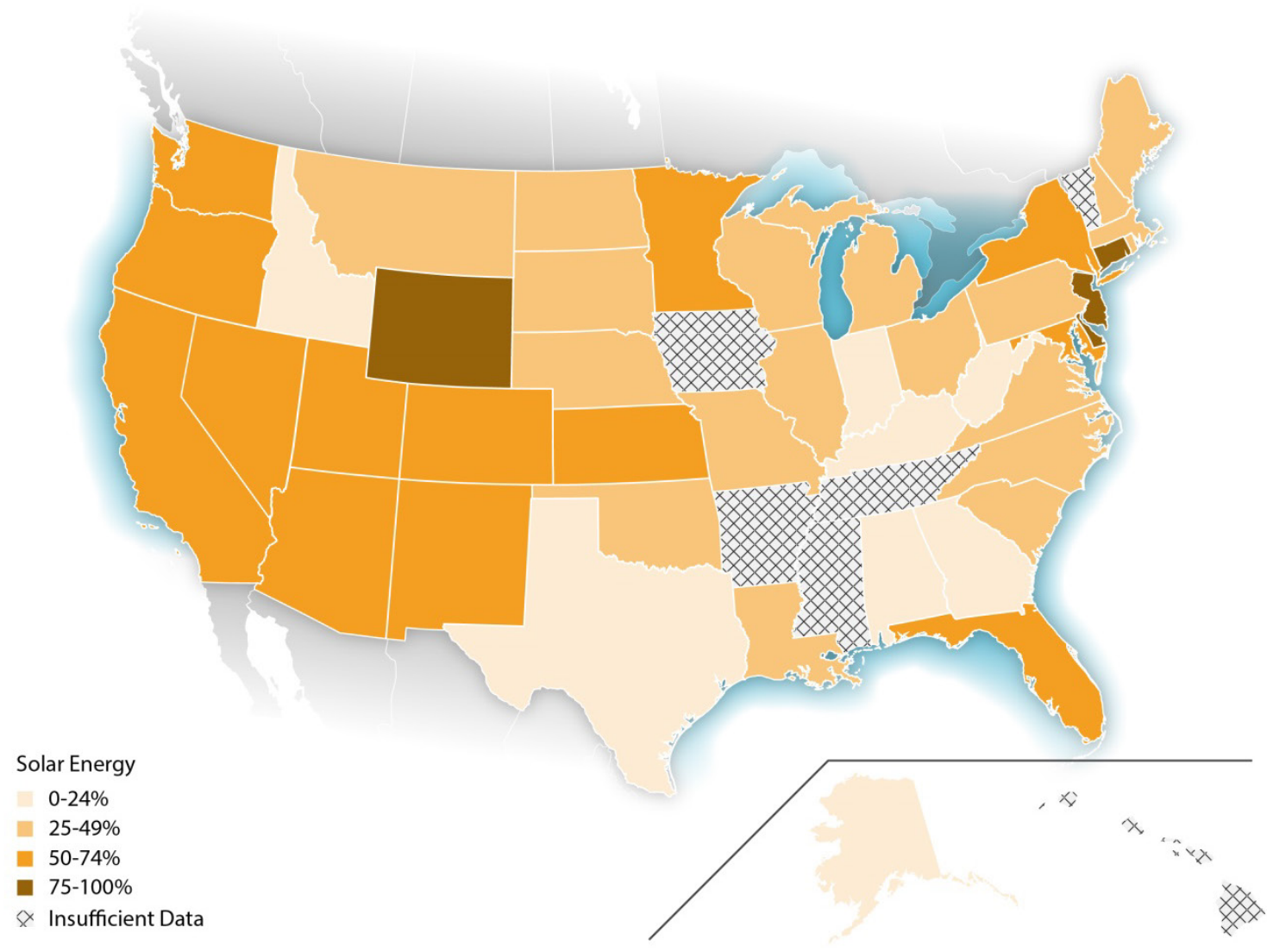

Figure 13. Percentage of municipal codes by state that reference the keyword solar

\footnotetext{
${ }^{33}$ There were 1,466 unique substantive references to keywords in the state adjusted samples and 1,402 such references in the national sample.

34 "Solar Maps," National Renewable Energy Laboratory, accessed April 22, 2016, http://www.nrel.gov/gis/ solar.html.
} 


\subsubsection{Reference Analysis Results}

To gain insight regarding how municipalities reference solar in their municipal code, we selected four states with high solar reference totals for additional analysis: California, Florida, Maryland, and Minnesota. ${ }^{35}$ In total, 145 municipalities within these states referenced solar in 370 unique sections of municipal code. Figure 14 illustrates the distribution of these references by policy category.

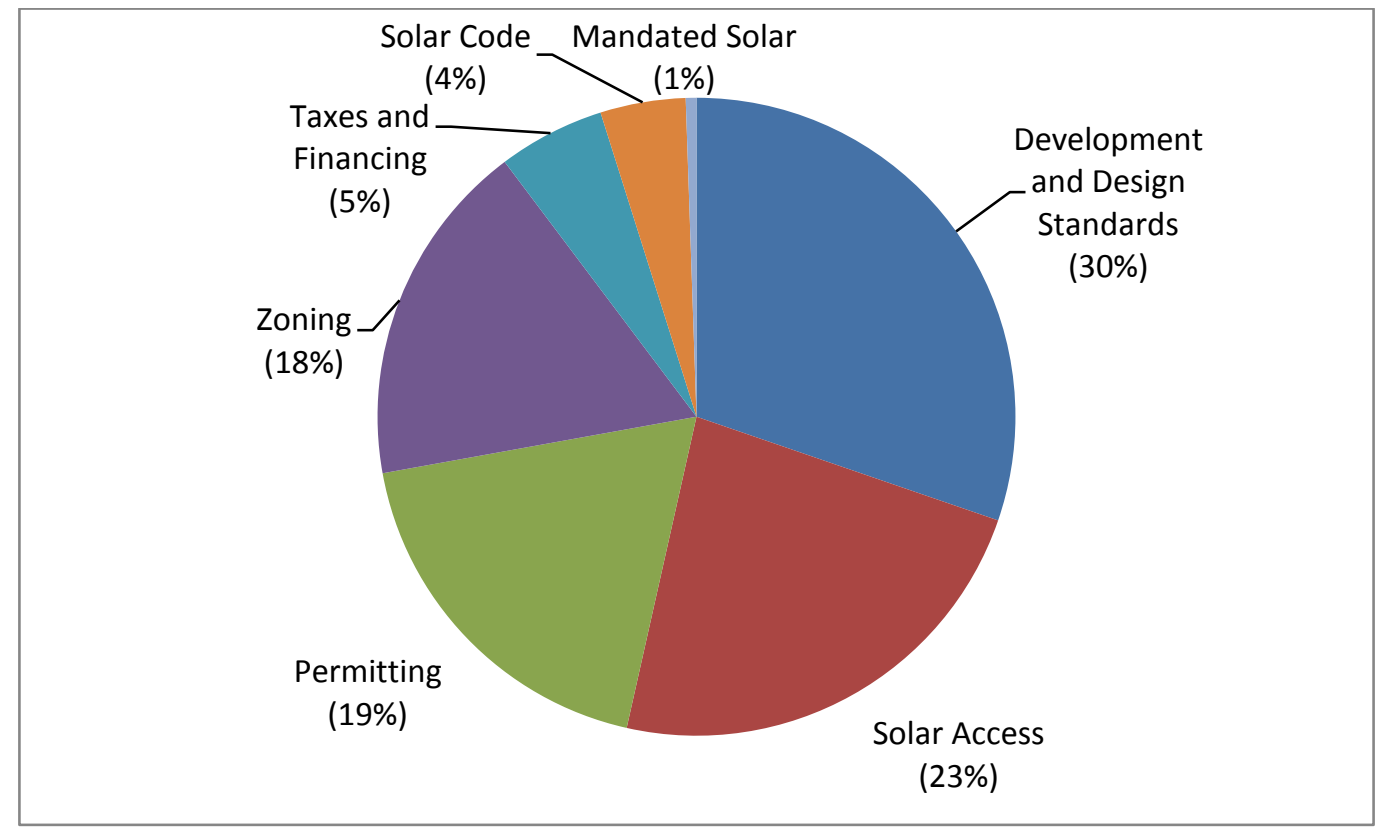

Figure 14. Unique substantive solar references by policy category

Thirty percent of all solar references relate to development and design standards. Quite often, these references exclude solar installations from building height requirements, require screening of solar equipment from public view, require systems to conform to the Uniform Solar Energy Code or other fire and safety codes, address setback requirements, or require other aesthetic, landscape, or building orientation changes among a myriad of other design-related stipulations. ${ }^{36}$ These references were also often directed at specific building types (e.g., single family homes) or zones (e.g., commercial or industrial zones).

Solar access-related references were the second-most common. These references generally dictate that one property may not impinge on neighboring properties' access to sunlight between 10 a.m. and 2 p.m. Many of the references in this sample prohibit new buildings from limiting an abutting property's solar access, require landscaping plans to minimize or mitigate solar access impacts, or include solar access as a consideration when addressing zoning variance requests.

The permitting and zoning categories are the third- and fourth-most referenced policy categories. The permitting category includes municipal government's efforts to set permit fees, clarify building permit review and enforcement protocols, exempt solar from certain permit

\footnotetext{
35 The solar category includes references to both solar water heating and PV.

${ }^{36}$ The references to the Uniform Solar Energy Code are all unique to California municipalities. This code addresses the installation and maintenance of solar energy systems and is maintained by the International Association of Plumbing and Mechanical Officials. It is available at http://www.iapmo.org/Pages/DownloadCenter.aspx.
} 
requirements, and require contractors to hold licenses or certifications to be able to install solar systems. The zoning references are largely similar across the municipalities and typically allow solar PV or solar water heating systems in particular zoning districts (e.g., agricultural, residential, or industrial districts) as accessory or secondary uses. ${ }^{37}, 38$

The remaining three categories have significantly fewer references, capturing about $10 \%$ of the total. Of these, the taxes and financing category accounts for half of the references. Within this category, some municipalities such as Brooksville, Florida have created tax incentives to draw the solar industry to their community. ${ }^{39}$ Others have incentivized solar adoption through leasing (e.g., San Jose, California) or through tax exemptions on solar installations (e.g., Frederick, Maryland). ${ }^{40}$

The solar code policy category includes municipal references to solar in which a whole section of code is directed toward solar. In these municipalities, all of the zoning, permitting, and design standard requirements were listed in one section of code. One example is Pinecrest, Florida, which among other stipulations requires all new buildings be "solar-ready" and those residential structures larger than 6,000 square feet to include either a solar water heater or a PV system. ${ }^{41}$ Finally, the mandated solar category includes references requiring solar installations. For example, Fresno, California requires all new public buildings to incorporate solar, while Lancaster, California sets minimum PV requirements for certain multi-family residential buildings based on the quantity of new residential units. ${ }^{42}$

\subsubsection{Wind Energy Reference Analysis}

As noted, wind energy is the second-most common keyword referenced with substantive mentions in 273 municipalities or $21 \%$ of the sample. Only four states in the sample have concentrations of wind references over 50\% (see Figure 15), while 17 states have concentrations of solar references over $50 \%$. In addition, the resource potential correlation identified in the solar data is not reflected in the wind reference data. For example, though South Dakota and Wyoming both have high wind resource potential and a high frequency of municipal references, Texas and New Mexico also have high wind resources but correspondingly fewer municipal references. ${ }^{43}$

\footnotetext{
${ }^{37}$ A secondary or accessory use refers to a PV installation that is associated with the main or primary use of a property, usually a building.

38 The tendency of municipalities to focus on solar as an accessory use indicates that municipal codification more often addresses solar energy generation associated with a building rather than solar installations that are the primary use of a property and which are often directly tied to the electrical grid. This tendency is also reflected in the development and design standards references.

${ }^{39}$ See Article III - Economic Development Incentive Ordinance, which is available at http://www.municode.com/.

${ }^{40}$ See San Jose Chapter 15.38 - Municipal Solar Utility Program and Sec. 8-10 - Property tax credit - Historic preservation property rehabilitation, which is available at http://www.municode.com.

${ }^{41}$ See Div. 5.27. - Alternative Energy Systems and Environmental Conservation, which is available at http://www.municode.com/.

${ }^{42}$ See Fresno, California Sec. 4-116. - Installation of Solar Energy Systems in Construction of New City-Owned Buildings and Lancaster, California 17.08.060 - Development regulations by building types, which is available at http://www.municode.com.

${ }^{43}$ See "WINDExchange: Potential Wind Capacity," DOE, accessed April 27, 2016, http://apps2.eere.energy.gov/wind/windexchange/windmaps/resource potential.asp and See "WINDExchange: Residential-Scale 30-Meter Wind Maps," DOE, accessed April 27, 2016, http://apps2.eere.energy.gov/wind/ windexchange/windmaps/residential_scale.asp.
} 


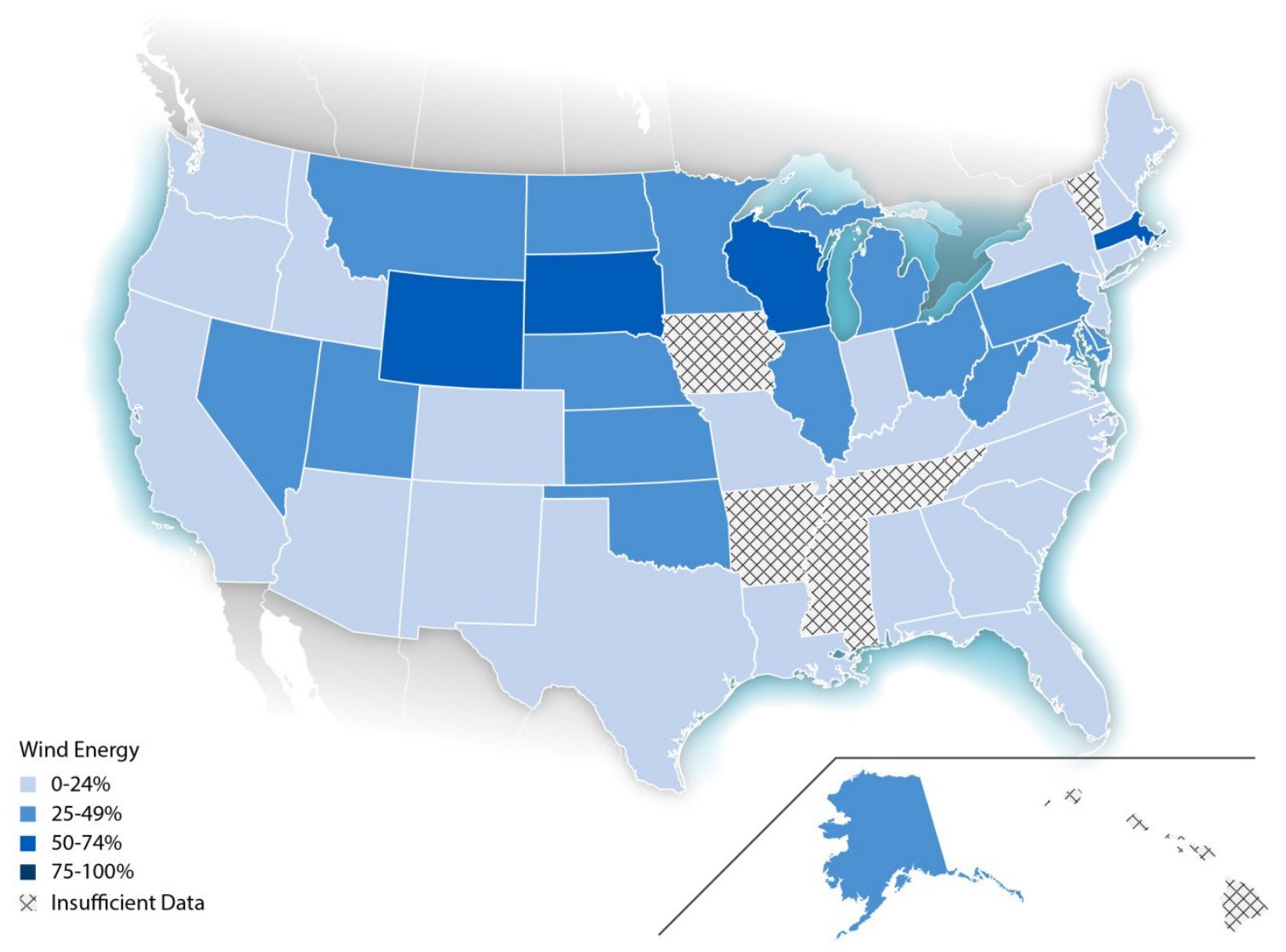

Figure 15. Percentage of municipal codes by state that reference the keyword wind energy 


\subsubsection{Wind Energy References}

To evaluate how municipalities reference wind energy, we selected 55 municipalities from four states (Illinois, New Hampshire, Ohio, and South Dakota) for subsequent analysis. There were 88 unique wind energy-related references across these municipalities. Figure 16 displays these references by policy category.

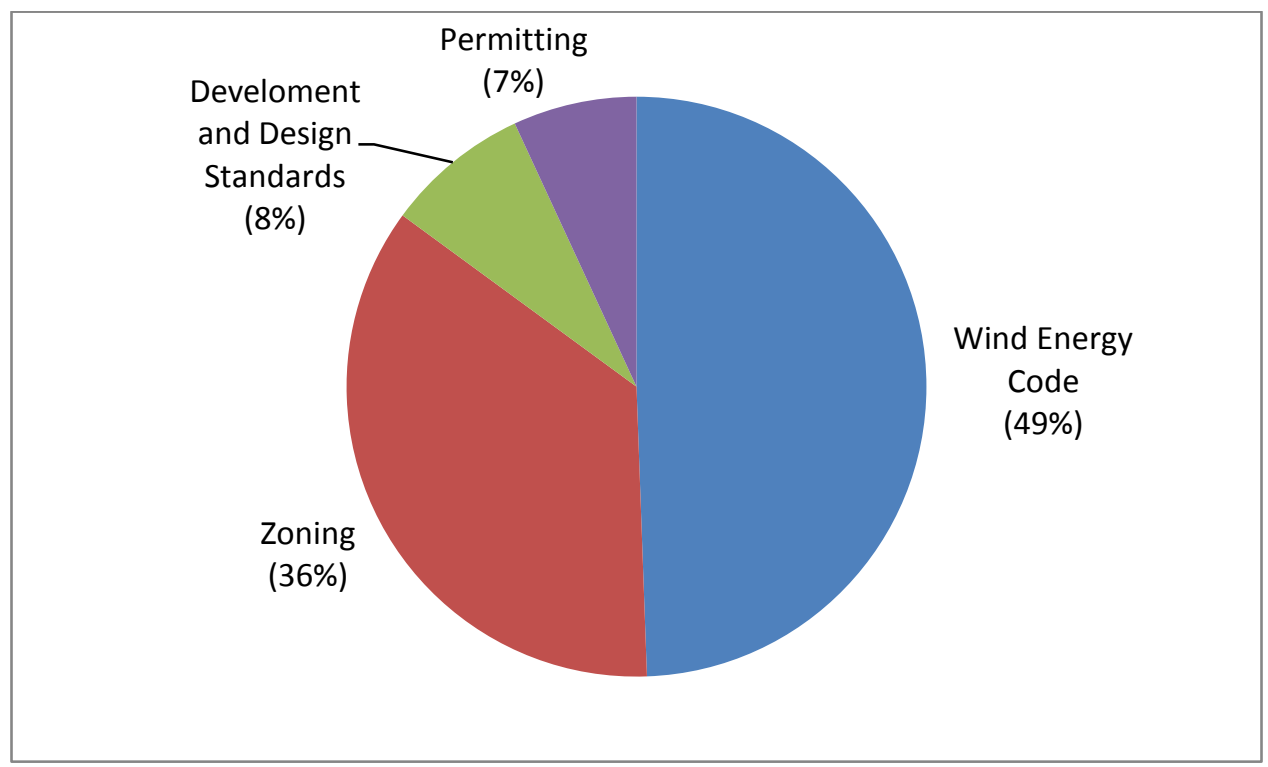

Figure 16. Unique substantive wind energy references by category

Unlike in the solar category, nearly half of the references to wind energy are associated with an all-encompassing wind energy code. Belvidere, Illinois and Brookings, South Dakota are two examples where wind energy zoning, permitting, development, and design requirements are all discussed in one section of code specific to wind energy. ${ }^{44}$ Zoning references were the secondmost frequent references, and they generally allow wind energy systems in certain zones as a special or conditional use. ${ }^{45}$

The development and design standards and permitting categories round out the wind energy references and cover the remaining $15 \%$ of the coded references. The development and design standard references nearly all address wind turbine height exceptions. ${ }^{46}$ Finally, the majority of references in the permitting category address application fees as is the case in Cary, Illinois. ${ }^{47}$

\footnotetext{
${ }^{44}$ For Belvidere, Illinois, see Sec. 150.714. - Wind Energy Systems Standards. For Brookings, South Dakota, see Sec. 94-367. - Small Wind Energy Conversion System (SWECS). Both are available at http://www.municode.com/. ${ }^{45}$ As an example, see Monroe, Ohio, 1205.01. - Accessory Uses, which is available at http://www.municode.com/. ${ }^{46}$ As an example, see Nashua, New Hampshire, $\$ 190-16$ Dimensional Regulations, which is available at http://www.ecode360.com/8732405\#8732405. The only reference in this category that does not exclusively address height requirements is Upper Arlington, Ohio's reference that specifies setback requirements, aesthetic considerations, and maintenance requirements. See Upper Arlington, Ohio, $§ 6.10$ - Conditional Uses, which is available at http://www.municode.com/.

${ }^{47}$ See Sec. 15.36.010. - Designated, which is available at http://www.municode.com.
} 


\subsubsection{Geothermal Reference Analysis}

Finally, 125 municipalities or about $10 \%$ of the sample references geothermal, making it the third-most frequently referenced keyword. ${ }^{48}$ Only in Delaware do more than $50 \%$ of municipalities reference geothermal. As with wind, those states with high geothermal resource potential, at least in terms of electricity production, are not strongly correlated with those states with higher geothermal references (Figure 17). For example, Arizona, Idaho, and Oregon have high geothermal potential but few references. ${ }^{49}$

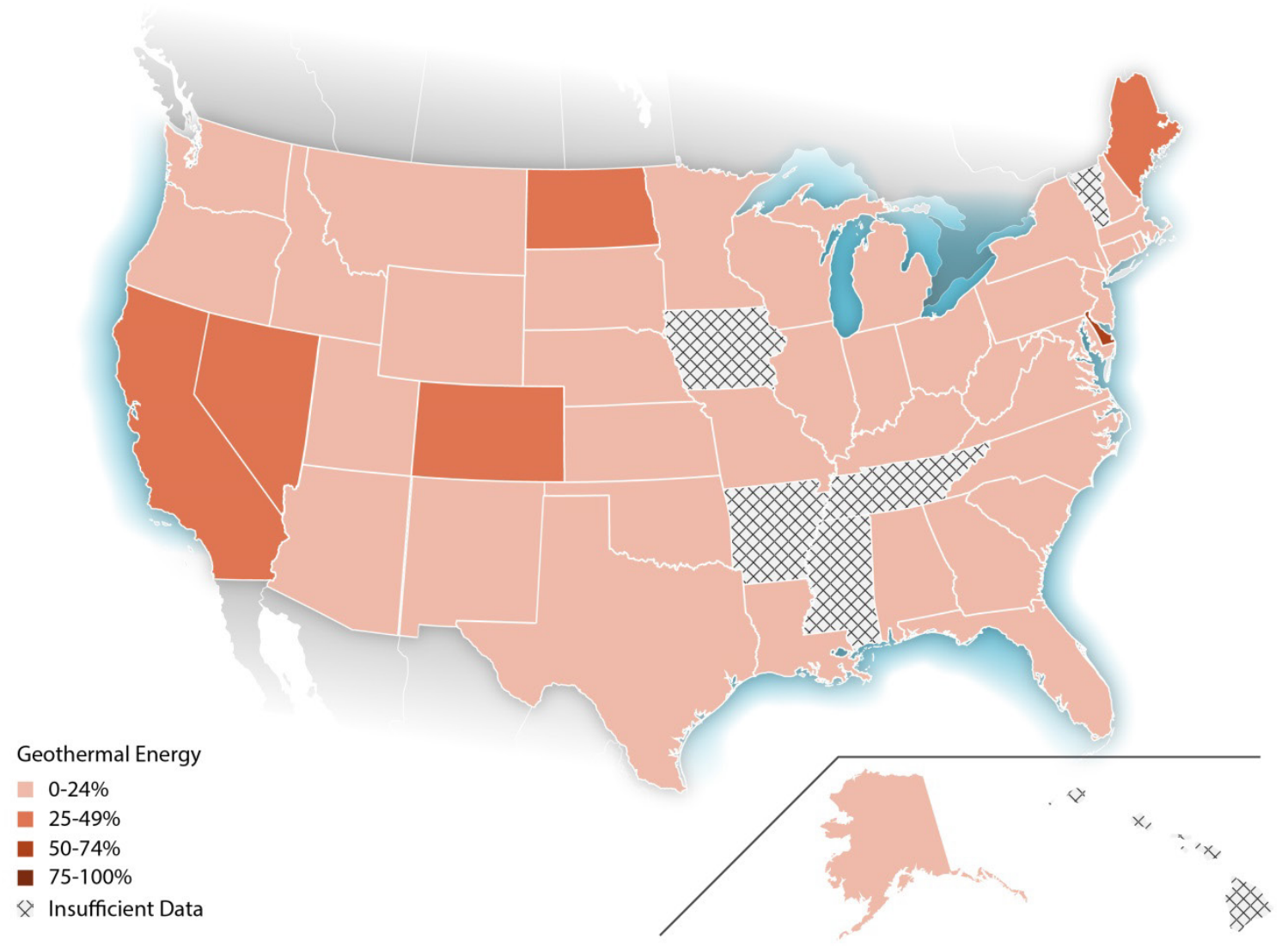

Figure 17. Percentage of municipal codes by state that reference the keyword geothermal

\footnotetext{
${ }^{48}$ The geothermal category includes references to both central station electricity generation and heating and cooling systems such as ground source heat pumps.

${ }^{49}$ See "Geothermal Resource of the United States: Locations of Identified Hydrothermal Sites and Favorability of Deep Enhanced Geothermal Systems (EGS)," NREL, accessed April 27, 2016, http://www.nrel.gov/gis/images/ geothermal_resource2009-final.jpg.
} 


\subsubsection{Geothermal References}

In this case, the lack of a relationship between geothermal electricity resource potential and references can be partially explained by how the states are referencing geothermal. Twenty-four municipalities across four states (Delaware, Colorado, Nevada, and Pennsylvania) had 45 unique substantive references to geothermal. A plurality of these references (46\%) directly addresses geothermal heating and cooling systems, while $33 \%$ of the references address large-scale geothermal electricity generation (all in Nevada) and 20\% do not specify technology. ${ }^{50}$ These references are collectively categorized by policy type in Figure 18.

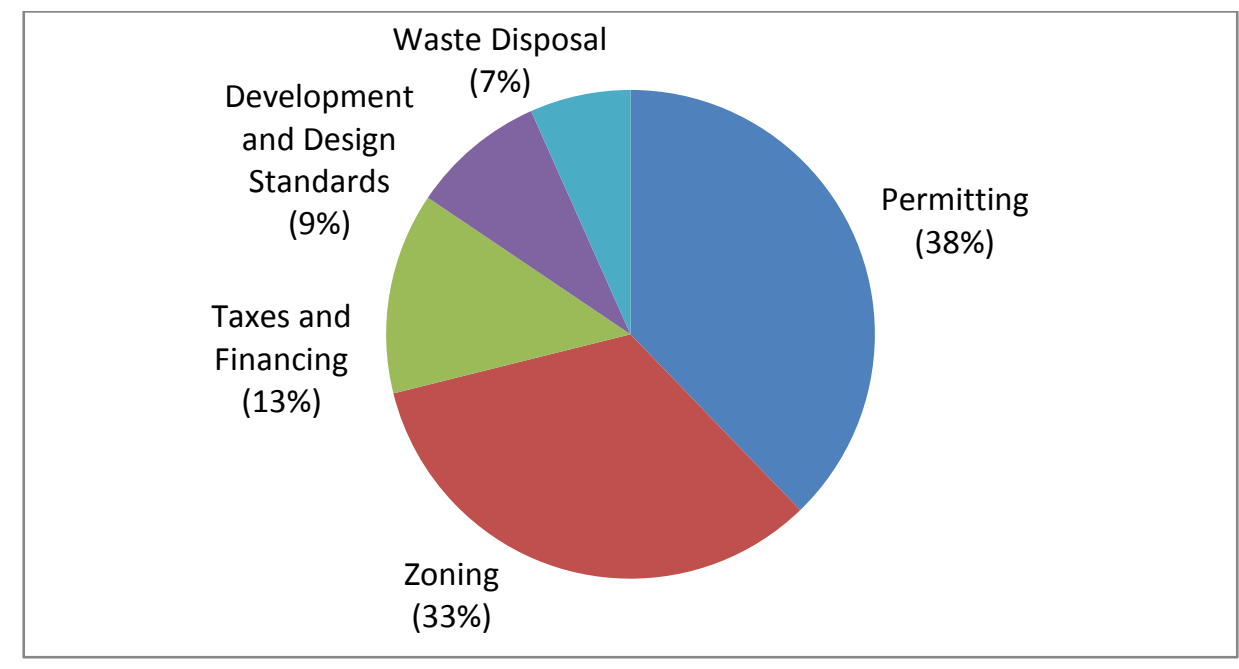

Figure 18. Unique substantive geothermal references by category

Almost $40 \%$ of the references relate to permitting, and nearly half of those, address geothermal in terms of building permit evaluation criteria. For example, Basalt, Colorado includes geothermal heating and cooling systems as a building component that counts toward point totals that are required to meet the community's sustainable residential building standards. ${ }^{51}$ The remainder of the permitting references relate to setting fees, application processes, and franchise agreement requirements for providing geothermal services; franchise agreement requirements are unique to Reno, Nevada. ${ }^{52}$

Zoning references, which were the second-most common references, most commonly address geothermal heating and cooling systems in relation to permitted secondary uses in certain zones; however, zoning references in Nevada typically address large-scale geothermal drilling operations. ${ }^{53}$ The taxes and financing category includes a myriad of references, but most often the references allow geothermal systems to qualify for specific programs. For example, Belfast, Maine allows geothermal to qualify for its property-assessed clean energy (PACE) financing

\footnotetext{
${ }^{50}$ For a discussion of these systems, see "Geothermal Heat Pumps," DOE, accessed April 27, 2016, http://energy.gov/energysaver/geothermal-heat-pumps.

${ }^{51}$ See Sec. 18-25. Point Details, which is available at http://www.municode.com.

${ }^{52}$ Reno, Nevada has granted some entities the authority to sell geothermal resources to customers within certain service areas provided they meet specified requirements. As an example, see Article VIII. - Skyline Area Geothermal Water Distribution, which is available at http://www.municode.com/.

${ }^{53}$ For example, see Carson City, Nevada 18.04.160 - Agriculture (A), which is available at www.municode.com.
} 
program, and Fort Collins, Colorado includes geothermal as a qualifying resource in its net metering program. ${ }^{54}$

All of the development and design standard references address geothermal wells and generally prohibit connections with the potable water supply. ${ }^{55}$ Finally, the waste disposal category is unique to the geothermal keyword; it relates to municipal prohibitions on discharging geothermal waters to public water treatment and waste management facilities. ${ }^{56}$

\subsection{The Relationship Between Clean Energy References and Market Penetration}

Given the expectation that references to clean energy within municipal code may influence the achievement of policy goals, it is useful to evaluate whether referencing certain clean energy keywords is related to higher market penetration. This type of analysis has been difficult to complete because of the challenges in accessing both municipal codes along with clean energy market data at the municipal level.

A recent NREL analysis (Day 2015) evaluated cumulative installed PV capacity through the end of 2014 for municipalities in Arizona, Georgia, Massachusetts, Minnesota, New York, and New Jersey. ${ }^{57}$ With the capacity data from this analysis, it is possible to evaluate whether municipalities in our sample that reference solar have higher PV capacity than municipalities within the sample that do not reference solar across these six states.

In each of the six states analyzed by Day (2015), those municipalities with a solar reference are found to have both higher aggregate installed PV capacity and higher installed watts per capita than municipalities with codes that do not reference solar (see Figure 19). Given this, there may be a correlation between solar code references and higher installed PV capacity, but more sophisticated analysis is necessary to determine whether this correlation exists, is present in other states, and reflects a causal connection. Anecdotal evidence suggests that cities often regulate solar through code in response to market interest and demand, which, while not creating market demand, may establish a regulatory pathway that accommodates adoption of solar technologies.

\footnotetext{
${ }^{54}$ See Belfast, Maine Article I. - Property Assessed Clean Energy Program and Fort Collins, Colorado Article IV. Electric. Both are available at http://www.municode.com/.

${ }^{55}$ As an example, see East Greenville Borough, Pennsylvania Article II: Cross-Connection Control §94-17, which is available at http://ecode360.com/10752749\#10752749.

${ }^{56}$ For example, see Sparks, Nevada Chapter 13.36 - Wastewater Regulations, which is available at http://www.municode.com/.

${ }^{57}$ Day (2015) gathered installed capacity data from state sources, including the Minnesota Department of Commerce, Southface Energy Institute in Georgia, the Massachusetts Department of Energy Resources, the New Jersey Department of Clean Energy, and OpenNY. For this analysis, cities within the sample with no state record of PV installations were cross-checked with U.S. Treasury Department data on installations that received a grant in lieu of tax credit under Section 1603 . We calculated total installed capacity and installed watts per capita using U.S. Census 2013 population estimates.
} 


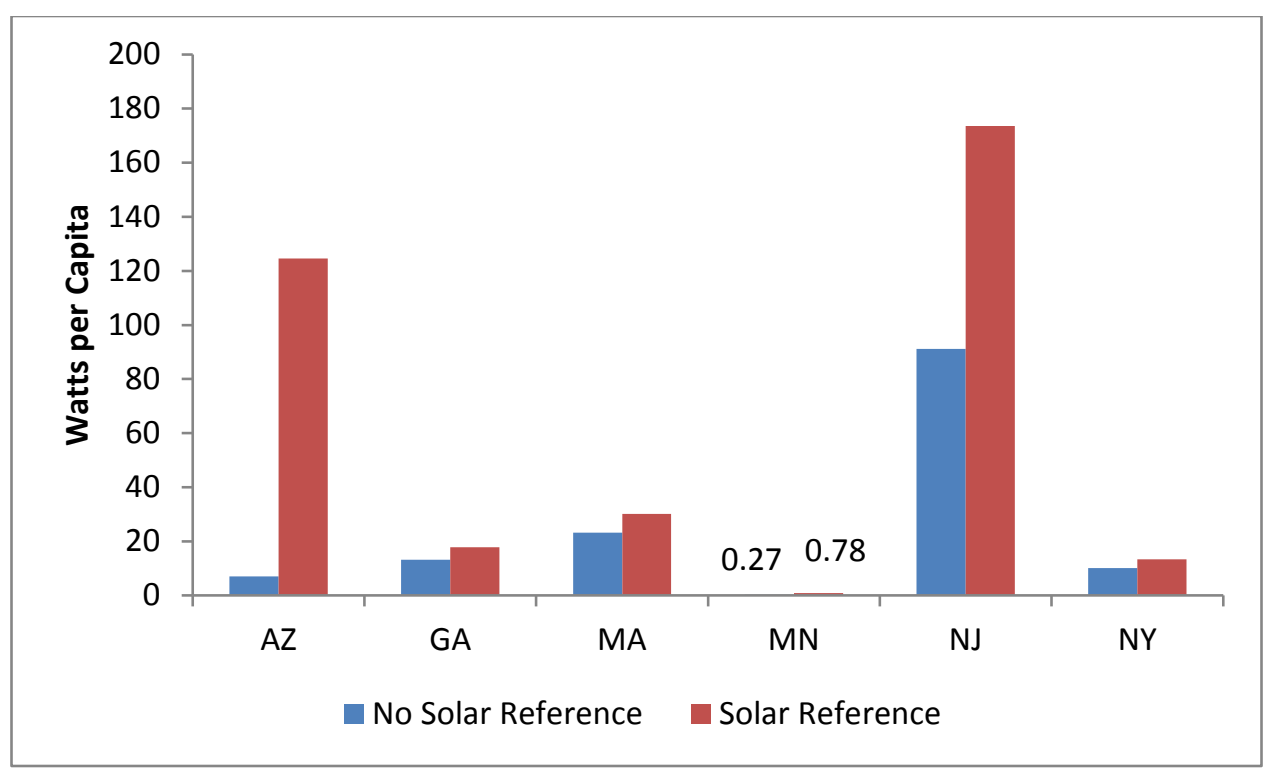

Figure 19. Average installed solar PV Watts per capita for municipalities across select states by substantive solar reference

Given data limitations, it was not possible to conduct a similar analysis evaluating the relationship between wind energy or geothermal references and installed capacity within each municipality. This type of analysis would be valuable to determine whether a similar relationship is present with these policy areas as well as with transportation.

\subsection{Energy Efficiency and Building Energy Codes}

The analysis of residential building energy code adoption at the municipal and state level serves to illustrate the scope of codification of energy efficiency. The ICC data set on municipal energy code adoption shows that municipal codification using IECC codes is widespread even in states where a statewide mandatory residential building energy code is present. Currently, 40 states have selected an IECC or equivalent standard that is at the 2006 level or beyond. ${ }^{58}$ In comparison, 535 self-reported municipalities in 33 states have adopted an IECC or other residential energy code. Municipalities typically adopt these codes under different conditions:

- Municipalities may adopt a residential energy code in the absence of a mandatory state energy code.

- Municipalities may adopt a residential energy code that is more aggressive than an outdated state energy code.

- Municipalities seeking higher energy performance goals may pursue "above-and-beyond" green/energy building standards.

\footnotetext{
${ }^{58}$ BCAP considers any code prior to IECC 2006 to be out of date. Codes prior to IECC 2006 do not achieve energy efficiency performance standards that are industry practice. The adoption of subsequent IECC versions, including IECC 2009, IECC 2012 and IECC 2015 results in incremental energy efficiency gains and a "raising of the bar" for residential construction practices.
} 
Figure 20 depicts municipal-level residential building energy code adoptions in states that have an existing mandatory residential building energy code and those states without a code (or with a code predating IECC 2006). Figure 21 illustrates those states in which at least one municipality has adopted a residential building energy code such as IgCC or ICC-700 that is considered above-and-beyond code. ${ }^{59}$

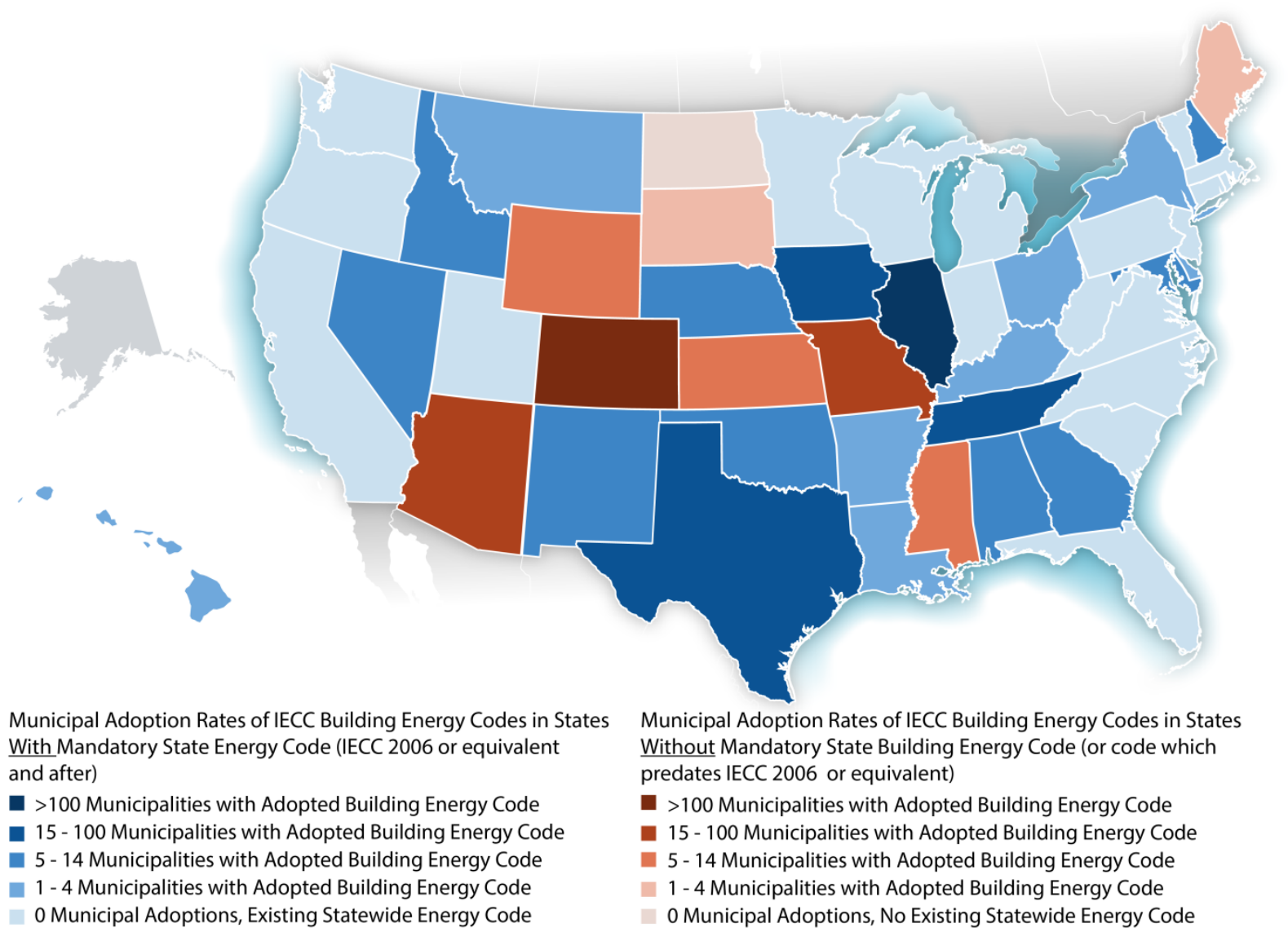

Figure 20. Municipal adoption rates of IECC building energy codes by state

a In cases where a state has zero municipal adoptions and an existing statewide energy code it may be the case that the jurisdiction's authority is subject to Dillon's Rule, where local authority for adopting a more stringent building code than the state code is limited. Possible examples may include Connecticut, Minnesota, North Carolina, Pennsylvania, Rhode Island, Vermont, Virginia, Washington, and Wisconsin

\footnotetext{
${ }^{59}$ The requirements in these codes exceed energy performance and green construction practices included in versions of IECC code (for IECC 2009 and IECC 2012).
} 


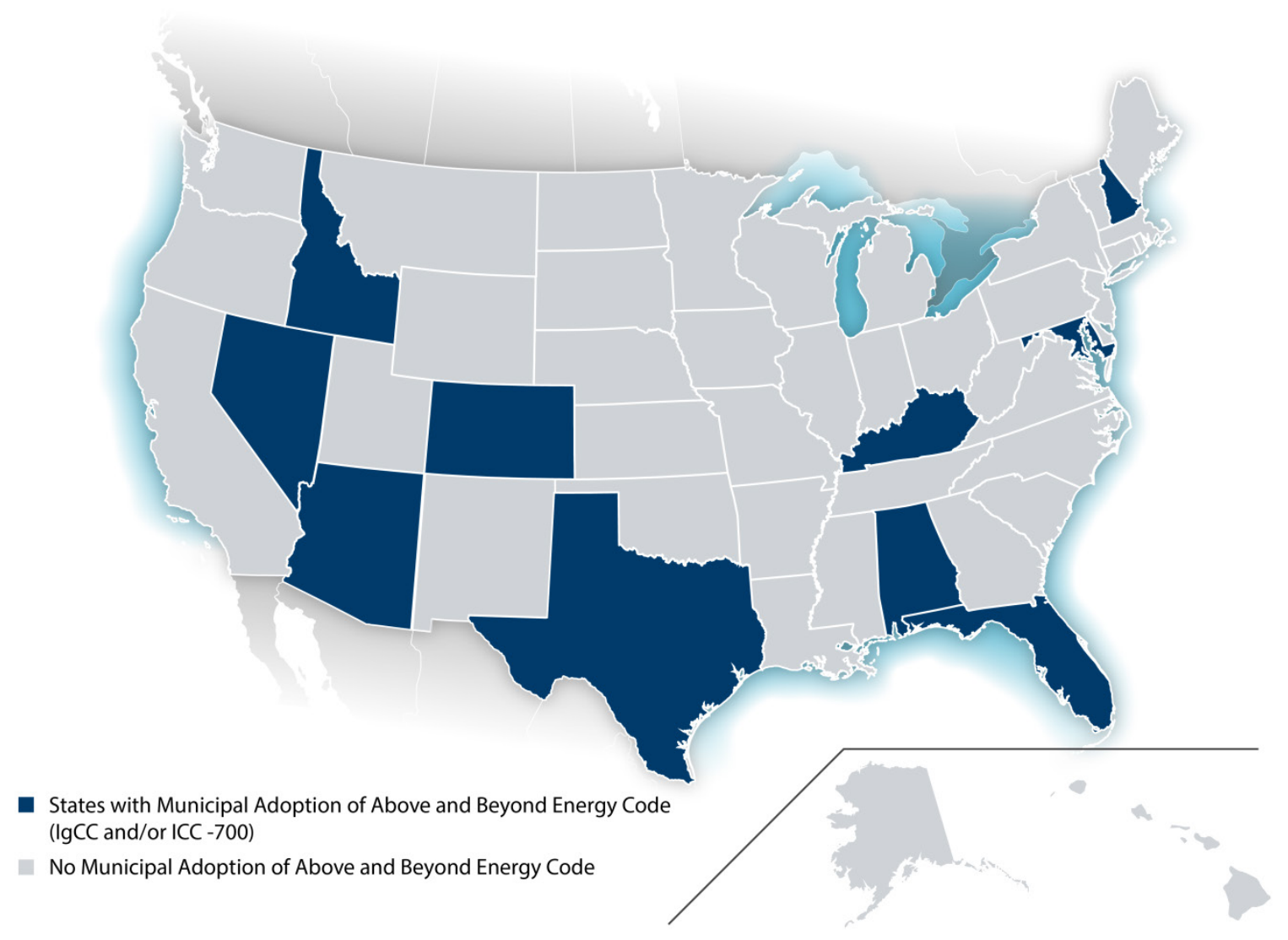

Figure 21. Municipal leadership in residential energy code adoption

The buildings code data set and Figures 20-21 allow three key observations. The first observation is that 229 of the 535 municipalities (43\%) adopting a residential energy code are located in states that either have an outdated residential building energy code or do not have one (Figure 20). Colorado and Arizona, with 130 and 41 municipalities respectively are standout examples of local governments filling the gap of building energy code regulation. The second observation is that at least one municipality in 10 states has enacted residential building energy codes that are considered above-and-beyond code (Figure 21). Colorado and Arizona have the highest rates of above-and-beyond code adoption with six and five municipalities respectively, while Alabama has three such municipalities and Florida, Idaho, Maryland, Nevada, New Hampshire, Texas, and Washington have one each.

The third observation from the data is that 167 municipalities have adopted a residential building energy code in states that have either adopted a new statewide code or updated an existing statewide code since January 1, 2015. Of these municipalities, 138 are located in Illinois, and these adoptions preceded Illinois' statewide IECC 2015 adoption in $2016 .{ }^{60}$ It is plausible that this municipal adoption contributed to the state's ultimate adoption of a statewide code.

\footnotetext{
${ }^{60}$ Illinois Energy Conservation Code (IECC 2012) was effective as January 11, 2013; Illinois Energy Conservation Code (IECC 2015) was effective January 20, 2016. The other states where municipal adoption preceded and potentially influenced state wide adoption include Idaho, Iowa, Maryland, Nevada, and Texas.
} 
The ICC data set does not cover commercial building energy codes as broadly as it covers residential codes, so it was not possible to conduct a similar analysis addressing the impact of these policies at the municipal and state levels. Subsequent work addressing the scope and impact of commercial energy code adoptions could strengthen, complement, and broaden the residential building energy code results discussed here. 


\section{Conclusions and Future Work}

The primary goal of this research was to evaluate the extent to which municipal governments with populations greater than 2,500 codify clean energy policy across the United States. While the use of clean energy keywords in municipal code varies across regions and states, this research demonstrates that about $60 \%$ of cities are using codification to address clean energy policy within their jurisdictions. Thus, it is clear that municipalities incorporate clean energy policy into their code.

Future work could examine the role of codification in shaping policy outcomes and clean energy goal achievement at the municipal level. Though our analysis shows that most municipalities sampled reference at least one clean energy keyword, future research could evaluate the impact and content of these references.

Subsequent analyses of installed wind generation capacity and geothermal heating and cooling system installations across municipalities both with and without keyword references would be useful in gauging the extent to which capacity and code are correlated in these technologies. Further exploring the more homogenous nature of the wind energy references would also be valuable. The prevalence of specific wind energy codes could be reflective of technology or market maturity and serve as a model for other technologies to achieve market maturity through codification.

Though the use of sustainable transportation-related keywords by municipalities is comparatively low, a similar analysis evaluating alternative fuel infrastructure, charging stations, and vehicle registrations in relation to references would serve a similar purpose. Expanding the transportation keyword reference analysis to include terms such as "complete streets," transitoriented development, and pedestrian-friendly would offer a broader picture of the extent to which communities address sustainable transportation in municipal code.

In this analysis, we only touched on how municipalities can influence energy efficiency policy within their jurisdictions. Based on our results, future research could test whether high levels of jurisdictional adoption are a driver for state-wide building energy code adoption. In addition, it is possible that home-rule authority is a driving factor for higher levels of jurisdictional adoption prior to statewide building energy code adoption; examples may include Arizona, Colorado, Iowa, Illinois, and Maine. A similar analysis related to commercial building energy codes would help clarify the extent to which municipalities use building energy codes to shape energy efficiency policy. Future work could also build out the energy efficiency baseline to include keyword analyses for terms such as benchmarking, demand side management, energy efficiency, and weatherization among others to devise a clearer picture of how municipalities address energy efficiency via codification.

To be clear, codification is only one of the three major policy mechanisms; municipalities can also use plans and programs to achieve clean energy-related policy goals. The effectiveness of codification and regulation may partially depend on context (e.g., the presence of local champions or favorable state policies). Functionally, municipalities also complement policy enacted through codification with plans, programs, and projects that further the achievement of energy goals. Thus, it is also important for future work to examine how these tools are used in 
combination and how doing so influences policy goal achievement. A comprehensive approach such as this is likely necessary before drawing conclusions regarding the value of any given mechanism to achieve policy goals.

Ultimately, our research demonstrates that municipalities are using codification to establish clean energy and transportation policy. Our work thus serves as a foundation on which to build a more comprehensive picture of how municipalities shape and implement energy policy in the United States. 


\section{References}

Alreck, P.L. \& Settle, R.B. (1995) The Survey Research Handbook, 2nd edition. Chicago:

Aznar, Alexandra, Megan Day, Elizabeth Doris, Shivani Mathur, and Paul Donohoo-Vallett. 2015. City-Level Energy Decision Making: Data Use in Energy Planning, Implementation, and Evaluation in U.S. Cities. Golden, CO: National Renewable Energy Laboratory. http://www.nrel.gov/docs/fy15osti/64128.pdf.

Bassett, Ellen, and Vivek Shandas. 2010. "Innovation and Climate Action Planning: Perspectives from Municipal Plans." Journal of the American Planning Association 76(4):435-450.

Busche, S. 2010. "Clean Energy Policy Analyses: Analysis of the Status and Impact of Clean Energy Policies at the Local Level." Contract 303: 275-3000.

Coenen, F., and M. Menkveld. 2002. "The Role of Local Authorities in a Transition Towards a Carbon-Neutral Society.” Kok, M.T.J., Vermeulen, W.J., Faaij, A.P.C., \& de Jager, D., eds. Global Warming and Social Innovation: The Challenge of a Climate Neutral Society. London: Earthscan Publications.

Cort, K.A., and Butner, R.S. 2012. An Analysis of Statewide Adoption Rates of Building Energy Code by Local Jurisdiction. Richland, Washington: Pacific Northwest National Laboratory.

Day, Megan. 2015. "Local Solar: What Do Leading Solar Communities Have in Common? It May Not be the Characteristics You Expect." Planning 81(11):28-33. http://www.nrel.gov/docs/fy16osti/64883.pdf.

Erikson, Peter, Michael Lazarus, Chelsea Chandler, and Seth Schultz. 2013. "Technologies, Policies, and Measure For GHG Abatement at the Urban Scale." Greenhouse Gas Measurement and Management 3(1-2):37-54.

Hirshfield Shayna and PJ Iyer. 2012. The Community Energy Champions Grant: Building Local Organizational Capacity to Catalyze Community Energy Behavior Change. ACEEE Summer Study on Energy Efficiency in Buildings. http://aceee.org/files/proceedings/2012/data/papers/ 0193-000205.pdf.

ICMA. 2010. "ICMA 2010 Sustainability Survey Results," accessed February 9, 2015, http://icma.org/en/icma/knowledge network/ documents/kn/Document/301646/ICMA_2010_Sus tainability_Survey_Results.

Irwin and Gay, L.R. \& Diehl, P.L. (1992). Research Methods for Business and Management. New York: Macmillan.

Mackres, Eric, Kate Johnson, Annie Downs, Rachel Cluett, Shruti Vaidyanathan, and Kaye Schultz. 2013. The 2013 City Energy Efficiency Scorecard. Washington, D.C.: American Council for an Energy-Efficient Economy. http://aceee.org/sites/default/files/publications/ researchreports/e13g.pdf. 
Martinot, Eric, Noriaki Yamashita, Vincent Tan, Risa Irie, Maryke Van Staden, and Monika Zimmermann. 2011. Global Status Report on Local Renewable Energy Policies. France. https://inis.iaea.org/search/search.aspx?orig_q=RN:46105568.

Riahi, Lily. 2015. District Energy in Cities: Unlocking the Potential of Energy Efficiency and Renewable Energy. United Nations Environment Programme, accessed February 6 2016, http://www.unep.org/energy/portals/50177/DES_District_Energy_Report full_02_d.pdf.

Ribeiro, David, Virginia Hewitt, Eric Mackres, Rachel Cluett, Lauren M. Ross, Shruti Vaidyanathan, and Sarah Zerbonne. 2015. The 2015 City Energy Efficiency Scorecard. Washington, D.C.: American Council for an Energy-Efficient Economy. http://aceee.org/sites/default/files/publications/researchreports/u1502.pdf.

Salon, Deborah Salon, Sinnott Murphy \& Gian-Claudia Sciara. 2014) "Local climate action: motives, enabling factors and barriers." Carbon Management 5(1):67-79. http://www.tandfonline.com/doi/pdf/10.4155/cmt.13.81.

Seto, K.C., and S. Dhakal. 2014. "Human Settlements, Infrastructure, and Spatial Planning." In Climate Change 2014: Mitigation of Climate Change. Contribution of Working Group III to the Fifth Assessment Report of the Intergovernmental Panel on Climate Change. O. Edenhofer, R. Pichs-Madruga, Y. Sokona, E. Farahani, S. Kadner, K. Seyboth, A. Adler, I. Baum, S. Brunner, P. Eickemeir, B. Kriemann, J. Savoloainen, S. Schlömer, C. von Stechow, T. Zwickel Eds. Cambridge University Press, Cambridge, UK, and New York.

Smart Growth America and National Complete Streets Coalition. 2015. The Best Complete Streets Policies of 2014. http://www.smartgrowthamerica.org/documents/best-complete-streetspolicies-of-2014.pdf.

Steinhoff, Mike, and Juan Wei. 2015. Measuring Up 2015: How US Cities Are Accelerating Progress Toward National Climate Goals. ICLEI - Local Governments for Sustainability USA, World Wildlife Fund, accessed February 7, 2016, http://icleiusa.org/wp-content/uploads/2015/ 08/Measuring_Up_2015.pdf.

Stout, S. 2014. "Jurisdictional Authority: Who has the (solar) power?" State and Technical Assistance Team Blog. National Renewable Energy Laboratory.

https://www.nrel.gov/tech deployment/state local governments/

blog/jurisdictional-authority.

Svara, James H., Anna Read, and Evelina Moulder. 2011. Breaking New Ground: Promoting Environmental and Energy Programs in Local Government. Washington, D.C.: IBM Center for the Business of Government. Conserving Energy and the Environment Series.

Tang, Zhenghong, Samuel D. Brody, Courtney E. Quinn, Liang Chang, and Ting Wei. 2010. "Moving From Agenda to Action: Evaluating Local Climate Change Action Plans." Journal of Environmental Planning and Management 53(1):41-62.

United States Conference of Mayors. 2011. The United States Conference of Mayors Clean Energy Solutions for America's Cities: A summary of Survey Results prepared by GlobeScan 
Incorporated and Sponsored by Siemens, accessed February 6, 2016, http://www.usmayors.org/ cleanenergy/report.pdf..

United States Conference of Mayors. 2008. "U.S. Conference of Mayors Climate Protection Agreement," accessed March 31, 2015, http://www.usmayors.org/climateprotection/ agreement.htm.

United States Census. 2016a. About Township Governments. http://www.census.gov/govs/go/state townships.html

United States Census Bureau. 2016b. Population of Interest-Municipalities and Townships. http://www.census.gov/govs/go/municipal township govs.html.

United States Census Bureau. 2012. Growth in Urban Population Outpaces Rest of Nation, Census Bureau Reports. Accessed February 12, 2016. https://www.census.gov/newsroom/releases/archives/2010 census/cb12-50.html.

Wheeler, Stephen M. 2008. "State and Municipal Climate Change Plans: The First Generation." Journal of the American Planning Association 74(4):481-496.

Wight, Colleen C. 2000. "Codification of Town Local Laws and Ordinances: Explained." Presentation for the New York State Association of Towns Annual Training School. General Code Publishers Corp. Accessed February 12, 2016. http://www.generalcode.com/codification/ guidelines-presentation/local-laws-ordinances. 


\section{Appendix A. Numbers of Municipalities in the Sample}

Table A-1. Total Municipalities by State and those Selected for National and State-Specific Samples

\begin{tabular}{|c|c|c|c|c|c|}
\hline State & Total Municipalities & $\begin{array}{l}\text { National Sample } \\
\text { (state sample) }\end{array}$ & State & Total Municipalities & $\begin{array}{l}\text { National Sample } \\
\text { (state sample) }\end{array}$ \\
\hline 1. Alaska & 19 & $5(9)$ & 26. Montana & 29 & $6(8)$ \\
\hline 2. Alabama & 152 & $30(30)$ & 27. Nebraska & 48 & $10(10)$ \\
\hline 3. Arizona & 75 & $15(15)$ & 28. Nevada & 15 & $3(10)$ \\
\hline 4. Arkansas & 106 & NA & 29. New Hampshire & 13 & $3(7)$ \\
\hline 5. California & 450 & $90(90)$ & 30. New Jersey & 248 & $50(50)$ \\
\hline 6. Connecticut & 23 & $7(7)$ & 31. New Mexico & 44 & $9(9)$ \\
\hline 7. Colorado & 98 & $20(20)$ & 32. New York & 275 & $56(56)$ \\
\hline 8. Delaware & 17 & $3(7)$ & 33. North Carolina & 222 & $44(44)$ \\
\hline 9. Florida & 267 & $55(55)$ & 34. North Dakota & 15 & $3(7)$ \\
\hline 10. Georgia & 209 & $41(41)$ & 35. Ohio & 359 & $71(71)$ \\
\hline 11. Hawaii & 1 & NA & 36. Oklahoma & 127 & $26(26)$ \\
\hline 12. Idaho & 52 & $10(10)$ & 37. Oregon & 104 & $21(21)$ \\
\hline 13. Illinois & 451 & $91(91)$ & 38. Pennsylvania & 377 & $75(75)$ \\
\hline 14. Indiana & 170 & $33(33)$ & 39. Rhode Island & 8 & $2(5)$ \\
\hline 15. lowa & 133 & NA & 40. South Carolina & 97 & $20(20)$ \\
\hline 16. Kansas & 102 & $20(20)$ & 41. South Dakota & 27 & $5(7)$ \\
\hline 17. Kentucky & 121 & $24(24)$ & 42. Tennessee & 143 & NA \\
\hline 18. Louisiana & 105 & $21(21)$ & 43. Texas & 509 & $103(103)$ \\
\hline 19. Maine & 20 & $4(7)$ & 44.Utah & 100 & $21(21)$ \\
\hline 20. Maryland & 66 & $14(14)$ & 45. Vermont & 11 & NA \\
\hline 21. Massachusetts & 53 & $10(10)$ & 46. Virginia & 86 & 19 (19) \\
\hline
\end{tabular}




\begin{tabular}{|l|c|l||l|c|c|}
\hline State & Total Municipalities & $\begin{array}{l}\text { National Sample } \\
\text { (state sample) }\end{array}$ & State & Total Municipalities & $\begin{array}{l}\text { National Sample } \\
\text { (state sample) }\end{array}$ \\
\hline 22. Michigan & 220 & $45(45)$ & 47. Washington & 149 & $31(31)$ \\
\hline 23. Minnesota & 225 & $46(46)$ & 48. West Virginia & 50 & $12(12)$ \\
\hline 24. Mississippi & 91 & NA & 49. Wisconsin & 217 & $45(45)$ \\
\hline 25. Missouri & 205 & $41(41)$ & 50. Wyoming & 25 & $6(8)$ \\
\hline
\end{tabular}

Six states (Arkansas, Hawaii, lowa, Mississippi, Tennessee, and Vermont) are excluded from the sample. They are indicated in the table as "NA." 


\section{Appendix B. Other Clean Energy Keywords Considered}

Table B-1. Clean Energy Keywords Considered but not included in this Analysis

\begin{tabular}{lll}
\hline Alternative Energy & Energy Efficiency & Sustainable Transportation \\
\hline Renewable Energy & ASHRAE & Bicycle Path/Bike Path \\
Renewable Resource & Benchmarking & Bus Rapid Transit \\
Alternative Energy & Density Bonus + Energy & Carbon Price \\
Fuel Diversity & District Energy & Carpool/Car Share \\
Resource Diversity & Energy Efficiency & Non-Motorized + Transit \\
& Energy Star & Ride Share \\
& Expedited Plan Review & Transit-Oriented Development \\
& International Energy Conservation Code & \\
& International Green Construction Code & \\
& ICC-700 & \\
& LEED & \\
\hline
\end{tabular}

